\title{
Mapping the Landscape of Creativity Support Tools in $\mathrm{HCl}$
}

\author{
Jonas Frich \\ Centre for Digital Creativity \\ Aarhus University \\ Aarhus, Denmark \\ frich@cc.au.dk
}

\author{
Lindsay MacDonald Vermeulen \\ Centre for Digital Creativity \\ Aarhus University \\ Aarhus, Denmark \\ lindsay.macdonald@cc.au.dk
}

\author{
Christian Remy \\ Centre for Digital Creativity \\ Aarhus University \\ Aarhus, Denmark \\ remy@cc.au.dk
}

\author{
Michael Mose Biskjaer \\ Centre for Digital Creativity \\ Aarhus University \\ Aarhus, Denmark \\ mmb@cc.au.dk
}

\author{
Peter Dalsgaard \\ Centre for Digital Creativity \\ Aarhus University \\ Aarhus, Denmark \\ dalsgaard@cc.au.dk
}

\begin{abstract}
Creativity Support Tools (CSTs) play a fundamental role in the study of creativity in Human-Computer Interaction (HCI). Even so, there is no consensus definition of the term 'CST' in $\mathrm{HCI}$, and in most studies, CSTs have been construed as oneoff exploratory prototypes, typically built by the researchers themselves. This makes it difficult to clearly demarcate CST research, but also to compare findings across studies, which impedes advancement in digital creativity as a growing field of research. Based on a literature review of 143 papers from the ACM Digital Library (1999-2018), we contribute a first overview of the key characteristics of CSTs developed by the $\mathrm{HCI}$ community. Moreover, we propose a tentative definition of a CST to help strengthen knowledge sharing across CST studies. We end by discussing our study's implications for future $\mathrm{HCI}$ research on CSTs and digital creativity.
\end{abstract}

\section{CCS CONCEPTS}

- Human-centered computing $\rightarrow$ Interaction design theory, concepts and paradigms; HCI theory, concepts and models; Interactive systems and tools.

\section{KEYWORDS}

Creativity Support Tools (CSTs); Creativity; Meta-Analysis; Literature Review

Permission to make digital or hard copies of part or all of this work for personal or classroom use is granted without fee provided that copies are not made or distributed for profit or commercial advantage and that copies bear this notice and the full citation on the first page. Copyrights for thirdparty components of this work must be honored. For all other uses, contact the owner/author(s).

CHI 2019, May 4-9, 2019, Glasgow, Scotland UK

(c) 2019 Copyright held by the owner/author(s).

ACM ISBN 978-1-4503-5970-2/19/05.

https://doi.org/10.1145/3290605.3300619

\section{ACM Reference Format:}

Jonas Frich, Lindsay MacDonald Vermeulen, Christian Remy, Michael Mose Biskjaer, and Peter Dalsgaard. 2019. Mapping the Landscape of Creativity Support Tools in HCI. In CHI Conference on Human Factors in Computing Systems Proceedings (CHI 2019), May 4-9, 2019, Glasgow, Scotland UK. ACM, New York, NY, USA, 18 pages. https://doi.org/10.1145/3290605.3300619

\section{INTRODUCTION}

Digital tools play an increasingly important role in almost all aspects of everyday life, not least in creative activities. From young children expressing themselves creatively by using an iPad app to make fanciful drawings, to professional record producers, photographers, architects, and designers; all rely on digital technologies to accomplish their creative tasks. This dependence on digital resources for creativity is reflected on Human-Computer Interaction (HCI), which has mainly explored themes pertaining to creativity by focusing on the potential of introducing various digital aids [152], more specifically Creativity Support Tools (CSTs) [154, 155]. As a subfield of HCI research, studies of CSTs were kickstarted twenty-five years ago, when Fischer [50] and Shneiderman [154] pointed out that computers had the potential to become tools for enhancing human creativity. HCI now features a sprawling range of research contributions centered around CSTs. Examples include Kim's [100] video tool for supporting novice videographers' creativity through expert heuristics, Wang et al.'s [173] automatically generated creativity stimuli for group brainstorming, and, recently, Ngoon et al.'s [126] work on improving creative feedback through an iterative system and Sullivan et al.'s [164] tarot-based narrative generation system for making short movie-like story synopses, to name but a few.

As these examples illustrate, the diversity of CSTs in HCI is wide. Although CSTs in this way have become integral to the CHI community's obvious interest in creativity, being 
centerpiece comes at a price. Creativity-oriented HCI research tends to favor the design and development of all-new CSTs [52]. This approach may entail the risk of 'reinventing the wheel,' since closely related, or similar, CSTs might already have been developed either in an HCI research lab or as one among the increasing number of off-the-shelf products that are not always given so much research attention despite many creative professionals' daily reliance on such existing brand-name CSTs. As shown in a recent survey [52], creativity-oriented research in HCI prioritizes development of new digital-interactive aids like CSTs that are clearly novel, but whose relevance and perceived affordances may not always be easy and simple to transfer to actual, contemporary forms of professional creative practice [51]. In practice, the majority of creative professionals-be it architects, digital designers, musicians, or visual artists-in many cases opt for tried-and-true CSTs as opposed to refashioning their workflows by testing new aids in an attempt to optimize or improve their day-to-day creative processes. This suggests the existence of a chasm between, on one side, the many (and diverse) CSTs that the CHI community develops in research labs and, on the other, what professional creative practitioners actually use.

This seeming discrepancy makes it thus more important to explore more comprehensively the array of CSTs emerging from various HCI research labs in order to bridge the gap between research labs prototypes and real-world professional needs. Additionally, the term 'CST' itself remains ill-defined, and few HCI studies of CSTs state explicitly how creativity is conceptualized in a particular context [52]. In sum, this makes it difficult to clearly demarcate this subfield of HCI research, let alone compare findings across CST-oriented studies. With more and more creative practices relying partly or even fully on CSTs, this current state of research in HCI is inexpedient in that it impedes scientific advancement and makes it significantly harder to get an overview of how this field of research looks, where it is, and where it is going. In other words, it is necessary to map the landscape of CSTs in $H C I$. We acknowledge the outcomes of the development of novel prototype CSTs that is integral to $\mathrm{HCI}$ as a research discipline. However, we wish to point toward an untapped potential in the CHI community's understanding of CSTs. In order to help accelerate further studies on CSTs as specialized contributions to the overarching category of digital creativity research, we argue that it is helpful-and indeed necessary-to take stock of the current body of CST research in $\mathrm{HCI}$ in order discern trends and future directions, and to build on insights from other fields, most prominently psychological creativity research, that can inform this research.

This paper's contribution to the CHI community is thus an overview of the key characteristics of CST-oriented research in HCI during roughly the past two decades. Based on a literature review of 143 publications from the ACM Digital Library (1999-2018), we highlight some of the main research interests and focal points in these studies. Informed by these findings, we propose a tentative definition of a CST to help scaffold future CST-oriented studies in HCI with the aim of improving knowledge sharing across studies. We end the paper by discussing implications of this literature review for the $\mathrm{CHI}$ community, and we suggest auspicious avenues for future research endeavors in this field.

\section{BACKGROUND AND RELATED WORK IN CREATIVITY RESEARCH}

Nearly twenty years ago, Shneiderman [153] proposed a framework to support the development of digital-interactive tools for creative problem solving, which is an established field in creativity research (e.g., [84, 85, 122]). In addressing the potential of advancing an individual's creative abilities through new tools, Shneiderman [153] considered commonly used, general-purpose tools like text editors and spreadsheets as well as more particular cases of architecture, graphics design, and engineering. The enhancement of creativity through technological support, as well as the development of a new discipline of creativity research and IT [19], should be attained by combining (at least) five research trajectoriesrefined theories, discussions of research methods, new software architecture, database management strategies and networking strategies, and improved user interfaces. These propositions were soon embraced by the CHI community. Reflecting upon the 1993 inaugural Creativity \& Cognition symposium, Candy and Hori [19] underlined the necessity to devote more attention to the examination and development of CSTs in order to benefit: "all people in any domain" [19, p. 54]. To accomplish this, however, the $\mathrm{CHI}$ community would: "need to understand much more about the creative processes that we are trying to support" [ibid.].

In the following years, research interest in CSTs grew; a development accelerated by a 2006 U.S. National Science Foundation workshop, which focused on CSTs and an imminent need to not only make creative processes more efficient, but, more importantly, users more innovative [157]. Here, Shneiderman advocated more audacity in the research on and development of CSTs, arguing that while the risks are high, "so are the payoffs for innovative developers, ambitious product managers, and bold researchers" [155, p. 22]. He even declared the development of new CSTs: "a grand challenge for HCI researchers" [156, p. 1].

As a synthesis of several pioneering, collaborative initiatives in the CHI community from the early 1990s-with critical contributions from related disciplines such as fine art, Artificial Intelligence, cognitive modeling, and design, etc. [19]-Shneiderman's programmatic proposal may be seen as 
reminiscent of another agenda-setting event. In 1950, Guilford [68] gave a presidential address to the APA (American Psychological Association) in which he accentuated the need for his peers to engage more profoundly and methodically in the study of creativity. Although seminal work had been published before, e.g., Wallas's [172] creativity process model with four phases-preparation, incubation, illumination, and verification-Guilford's address is now generally considered the beginning of modern-day creativity research [147, p. 16]. In the heyday of American behaviorism and its reluctance to study anything that could not actually be seen, Guilford boldly argued that creativity could be studied objectively by examining (internal) cognitive processes [144, p. 8] and that the: "neglect of this subject [creativity] by psychologists is appalling. The evidences of neglect are so obvious that I need not give proof" [68, p. 445]. What could have been an awkward moment became the catalyst for a novel research agenda that, while carried by psychology, soon branched out to several kindred disciplines.

Retrospectively, the ensuing upsurge of research has come to be considered the first wave of creativity research [147]. Methodologically, psychometrics, often devised as tests of divergent thinking, gained much attention. This was to some extent propelled by Guilford's studies of aspects of the human intellect (e.g., [69]), which he eventually synthesized in his Structure of the Intellect (SI) model [70]. Shared research interests were studies of the individual's cognitive abilities and the personality of the creative genius. Although later criticized for ignoring that "the validity of the SI model is in the eye of the beholder" [23], Guilford's studies proved influential and instrumental in the lead-up to a new era of creativity research [144]. In the early 1980s, a new generation of creativity researchers began to challenge the previous body of research, arguing for a lack of appreciation of the socio-cultural aspect of creativity, i.e., that creativity be seen as situated and thus context-dependent. Here, Amabile's [5] work on socio-psychological aspects of creativity was prominent. This led to the so-called second wave of creativity research [147], which dominated the late 1980s and early 1990s and foregrounded themes of groups and collaboration and the underlying cognitive processes as creativity unfolds in socio-cultural settings. Among the influential contributions was Finke, Ward, and Smith's [48] research on creative cognition, which helped pave the way for more openness toward new, interdisciplinary approaches to creativity in admittance of the fact that, as Gardner [56] put it, "creativity is precisely the kind of problem which eludes explanation within one discipline" [56, p. 22].

Compared to nearly seven decades of pathbreaking contributions from psychological creativity research, it is evident that HCI-oriented creativity research does not have an equally strong research tradition. Even so, there is now a conference dedicated to this special research interest (the Creativity \& Cognition symposia were established as an ACM SIGCHI conference in 1999), the number of creativitydirected publications by the $\mathrm{CHI}$ community has increased dramatically since the late 1990s [52], and even HCI-specific methods for measuring the impact of new CSTs have been offered [27]. This evolution of HCI research has sparked the idea of a potential third wave of creativity research [52], which may still be at an early stage compared to the bigger and more distinct first and second waves, respectively. It has been argued that this potential third wave is characterized by a focus on collaborative work and digitization, particularly the increasing dependency on CSTs in creative processes, and predominantly empirical research methodologies [ibid.].

We position the work presented here within this argued third wave of creativity research. In acknowledgment of the need to further strengthen collaboration between (psychological) creativity research and HCI research [51], we deem it important to unfurl our understanding of creativity. Our work is based on a broad definition of creativity according to which: "creativity is the interaction among aptitude, process, and environment by which an individual or group produces a perceptible product that is both novel and useful as defined within a social context" [135, p. 90]. Similarly, we wish to clarify our choice of terminology on an analytical level. Since Wallas' [172] four-stage model close to a century ago (1926) and, equally influential, Rhodes' [140] 4P framework of person, product, process, and press (from the milieu), the latter theme in particular has become increasingly important in the study of creativity. Among numerous creative process models (for an overview, see [147, p. 89]), Amabile's [4-6] 'componential theory of creativity' has had a strong impact on the creativity research community. This model includes four steps in the creative process-problem or task identification, preparation, response generation, and response validation and communication. Additionally, the creative process is nurtured by domain-relevant skills, creativity-relevant processes, and intrinsic task motivation. Runco and Chand [145] offered an even simpler model of the creative process with only three stages-problem finding, ideation, and evaluationwith knowledge and motivation being mutual influences. Here, we draw upon these established conceptualizations of creativity and the creative process when we examine the key characteristics of CSTs in what we believe may be an emergent third wave of creativity research, where specialized and established creativity research interests from the APA and $\mathrm{CHI}$ community, respectively, come together in attempt to further advance understanding of digital creativity.

\section{METHODOLOGY}

In this section, we provide a detailed description of the sampling method we used to gather literature about creativity 
support tools, as well as how we developed the categories for analyzing the surveyed literature. Our approach was inspired by previous survey papers such as Liu et al. [105] and Frich et al. [52], who have respectively provided overviews of 1) the field of $\mathrm{HCI}$ in general, and 2) creativity research within $\mathrm{HCI}$

\section{Sampling}

As the purpose of this paper is to map the landscape of CSTs in $\mathrm{HCI}$ research as it currently looks as well as point toward an updated definition of CSTs, we focused on sampling CSTs created by researchers rather than commercially available tools. We chose this focus on the following grounds:

Firstly, a recent survey has demonstrated that the majority of creativity-related research in $\mathrm{HCI}$ over the past two decades have focused on CSTs developed by researchers [52].

Secondly, such contributions generally offer thorough descriptions of the tools, their intended use, and their intended user groups.

Thirdly, the presentation of a new CST developed by HCI researchers is usually accompanied by an evaluation, providing some us with an assessment of its potential use in context.

The recent literature review of creativity research in $\mathrm{HCI}$ by Frich et al. [52] starts with a comprehensive and inclusive framing, as their initial sampling includes all publications that have either any occurrence of the word 'creativity support tool' or the author keyword 'creativity.' The latter ensures to capture papers, which did create CSTs, but without using the specific term, making this inclusion useful for our approach. In our survey in this paper, we reduced the sample from 998 to 221 papers by using average number of citations per year (0.669) as a cut-off point, thereby focusing on the most influential and widely acknowledged publications. Since we are mostly interested in HCI's opportunities to explore and create novel ways to support creativity, we have selected the subset labeled "New Tool" [52, p. 1244].

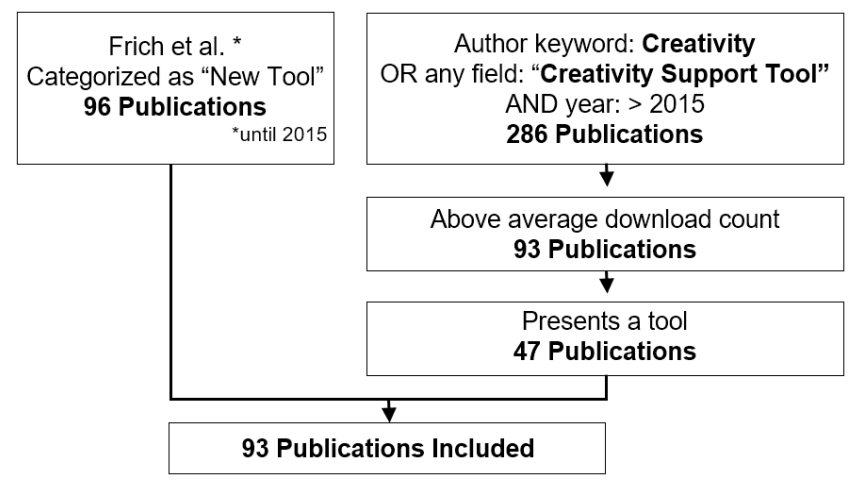

Figure 1: Selection criteria and number of papers included.

\begin{tabular}{|c|c|}
\hline Category & Codes \\
\hline Device & $\begin{array}{l}\text { - Analogue } \\
\text { - Phone/Smartphone/PDA } \\
\text { - Tabletop display } \\
\text { - Large wall display } \\
\text { - Tablet } \\
\text { - Laptop/Computer } \\
\text { - Tangibles } \\
\text { - Method/no device } \\
\text { - Miscellaneous }\end{array}$ \\
\hline Complexity & $\begin{array}{l}\text { - Low: One or two features } \\
\text { - Medium: Multiple feat., semi-complex system } \\
\text { - High: Entire system or suite of tools }\end{array}$ \\
\hline $\begin{array}{l}\text { Current } \\
\text { Availability }\end{array}$ & $\begin{array}{l}\text { - Not available } \\
\text { - Readily available online but needs hardware } \\
\text { - Online but requires user overhead to set up } \\
\text { - Readily available/usable online with no setup }\end{array}$ \\
\hline Maturity & $\begin{array}{l}\text { - Vision Description/Design Fiction/Scenario } \\
\text { - Lo-fi prototype or Mockup (Paper/WoOz) } \\
\text { - Hi-fidelity working prototype } \\
\text { - Public Release } \\
\text { - Longstanding Public Release/widely adopted }\end{array}$ \\
\hline $\begin{array}{l}\text { Part of } \\
\text { Creativity } \\
\text { Process }\end{array}$ & $\begin{array}{l}\text { - Pre-ideation/background research } \\
\text { - Idea generation or ideation } \\
\text { - Evaluation or critique } \\
\text { - Implementation } \\
\text { - Iteration } \\
\text { - Meta or project management }\end{array}$ \\
\hline User Group & $\begin{array}{l}\text { - Novice } \\
\text { - Casual user } \\
\text { - Expert } \\
\text { - Unspecified } \\
\text { - Intended audience } \\
\text { - Application domain/activity }\end{array}$ \\
\hline Evaluation & $\begin{array}{l}\text { - No evaluation } \\
\text { - Hypothesis-driven } \\
\text { - Exploratory } \\
\text { - Number of participants } \\
\text { - Student evaluators } \\
\text { - Qualitative } \\
\text { - Quantitative } \\
\text { - Mixed methods } \\
\text { - Method } \\
\text { - Criterion (what was evaluated for) }\end{array}$ \\
\hline $\begin{array}{l}\text { Collab- } \\
\text { oration }\end{array}$ & $\begin{array}{l}\text { - Individual use } \\
\text { - Collaborative use (with people) } \\
\text { - Collaborate with software/algorithm }\end{array}$ \\
\hline
\end{tabular}

Table 1: Categories and codes for the analysis. Codes in italics are open-ended codes for text input.

One of those was excluded [188] because although it presented a new tool, the majority of the paper focused on the method rather than the presentation and explanation of the tool. This yielded a total of 96 publications. 


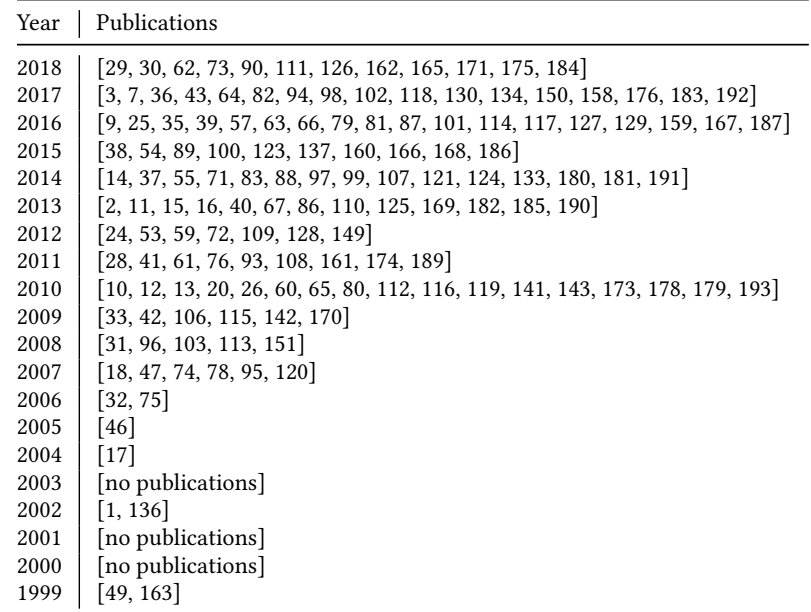

Table 2: List of surveyed papers, sorted by year.

In the survey from Frich et al., papers after 2015 are excluded. Due to the increase in creativity research in recent years, and in order to capture recent trends and developments in a rapidly evolving field of $\mathrm{HCI}$, we sought to fill the gap from 2015 to 2018. As the average citation is not a suitable metric for very recent papers due to a certain 'incubation time,' to accrue citations, we opted for the only other publicly available as well as least subjective metric-number of downloads from the ACM Digital Library. This allowed us to include papers published in the past three years.

For the sake of continuity and transparency, we applied a similar query and sampling as Frich et al. [52], but considered the average download count for each year individually in order to compute the cut-off for our sample. In total, we included 47 additional papers. The detailed numbers and selection criteria can be found in Figure 1. In summary, we examined an additional 286 publications, 93 of which were above the average download count and surveyed in more detail. Of those 93, 47 presented a tool rather than focusing on a method only. This left us with a total sample size of 143 publications from 1999 to 2018. An overview of the sampled papers for each year can be seen in Table 2 (note that due to sparse numbers of papers on CSTs in the early years of our sample, there are no papers from the years 2000, 2001, and 2003).

\section{Analysis}

For the analysis of our sampled papers, we developed a coding scheme to discover and study specific characteristics of the CSTs presented. Three researchers were in charge of reading and analyzing the corpus of all of the sampled papers, and the scheme was derived and refined through multiple iterations.
As a preliminary step, we started with a card-sorting activity with each card comprising a representative image and a summary of the paper's content. A set of rough codes emerged from this activity, which we tested by coding a random sample of five papers chosen from the chronological middle of the corpus by all three researchers independently. The resulting analysis was cross-checked and discussed to refine and expand the coding scheme, but also to ensure that all codes were interpreted similarly by all three researchers. This step was repeated, this time with a sample of five papers spread over a wider array of years in the corpus. Disagreements, although comparatively minor, were addressed by adding a dynamic, but concise description to the specific codes in the scheme.

The entire list of resulting codes is presented in Table 2. All 143 publications were randomly distributed between the three researchers, who read and analyzed each individual publication. Six codes were open-ended fields for text input (highlighted in italics in Table 1): 'Miscellaneous' in the device category was used to indicate special-purpose hardware being used in the CST, e.g., wearables, a pen, or a prototyping toolkit. 'Intended target audience' and 'domain/ activity' in the user group category were introduced to arrive at a uniform description of the application area. While target audiences sometimes were quite vague (e.g., children or designers), the domain field allowed us to be more specific.

In the evaluation category, three open-ended fields were 'number of participants,' 'method,' and 'criterion.' Contrary to our expectations, the number of participants was not a purely numeric field, since the reporting was not consistent among all papers. Some CSTs were evaluated in multiple steps in the true spirit of the iterative design cycle, in which case conflating or averaging the individual numbers would have been questionable. Another observation was that some evaluations only reported on number of teams. The variety in sample size (from small-scale, preliminary usability tests with $n=1$ to large-scale MTurk tasks with $n=173,053$ ) also makes reporting on an average or mean less insightful. Similarly, the variety in methodology made it infeasible to arrive at uniform descriptions for the method and criteria used in evaluation. An in-depth analysis of the evaluation of CSTs merits a paper on its own, which is why we only touch briefly upon the evaluation category in the results section. We reflect on the issue of evaluating CSTs in the discussion of this paper and posit it with regard to other ongoing discussions of the intricate problem of evaluation, both in HCI research and more established (psychological) creativity research.

\section{RESULTS AND SYNTHESIS}

We report our findings from the review in three tiers-focusing on the tools themselves, the research on the tools, and the 
trends and tendencies of this research. The results are visually represented in the following stacked bar charts (Figures 2-8). We discuss the results first as total numbers across all years sampled, then move on to discuss particular trends in the data over time.

\section{Devices Supported}

The various types of devices represented in our sample is shown in Figure 2. The vast majority of the publications reviewed describe CSTs intended for use on digital devices. (92\%, 131 publications), with most intended for use on a laptop or personal computer (52\%, 75 publications). These include both web-based and standalone applications, e.g., IdeaHound [159], aimed at supporting creativity through semantic modelling of the spatial structure of a solution space. CSTs intended for miscellaneous or specialized devices that do not fit into our main device categories account for $\sim 25 \%$ of our sample (36 publications). These include specialized music hardware devices (e.g., [55, 83]) and customized interactive environments built for dance (e.g., [151]). CSTs for tangible computing devices represent $\sim 17 \%$ of our sample (25 publications). Tangible tools come in many forms, with one example being Naruhodo Button by Yoshida et al. [187], who provide a study of a positive feedback button for brainstorming sessions using audio. Tablet-based CSTs comprise $\sim 14 \%$ (20 publications). An example of this is Co-3Deator [134], a highly collaborative 3D design ideation tool intended for tablet and stylus/pen. Wall-sized display CSTs make up $\sim 13 \%$ of our sample (18 publications) and smartphones $6 \%$ (8 publications).

Few of the papers reviewed present a purely analog CST; that is, a CSTS that does not require the use of digital or electronic hardware to function ( $6 \%, 9$ publications). Often,

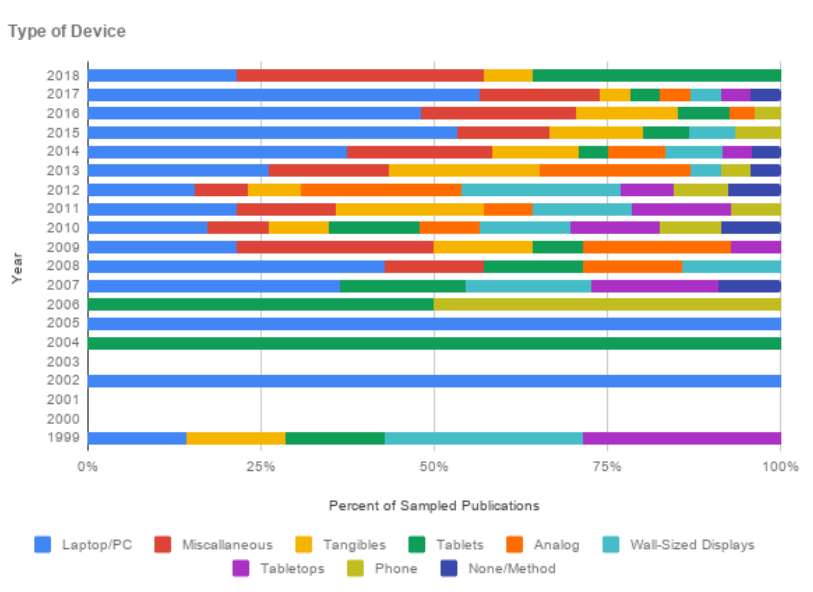

Figure 2: Devices intended to support CST use. these analog tools came in the form of card decks, e.g., work by Hornecker et al. [80], Envisioning Cards [53], or Exertion Cards [121].

\section{Complexity}

We analyzed the complexity of the CSTs in our sample, the results of which are shown in Figure 3. We found that $48 \%$ (68 publications) are low complexity, i.e., contain one or two features or accomplish one or two types of specific tasks. Aquamarine [123] is an example of a CST with low complexity, as it provides one single feature-the ability to selectively undo single actions in creative applications, e.g., brush strokes, rather than sequentially stepping backwards as in the current linear undo model.

CSTs with medium complexity, i.e., have multiple features and a semi-complex system, account for $43 \%$ (61 publications). A recent example of a medium complexity CST is IdeaMaché [94], which aids information-based ideation through the curation of various types of media, including sketching, writing, and perspective-shifting features.

Only $4 \%$ of our sample contained highly complex CSTs that provide an entire system or a whole suite of tools (6 publications). High-complexity tools like the Tele-immersive Dance Environment [151] that provides real-time, distributed collaboration via 3-D virtual rooms from multiple viewpoints, are more rare.

\section{Maturity of Tools}

Most of the CSTs in our sample are high fidelity prototypes (65\%, 93 publications), meaning that the tool exists as functioning implementation, but not yet available as a stable release. An example of this is Motif [100], a CST for mobile

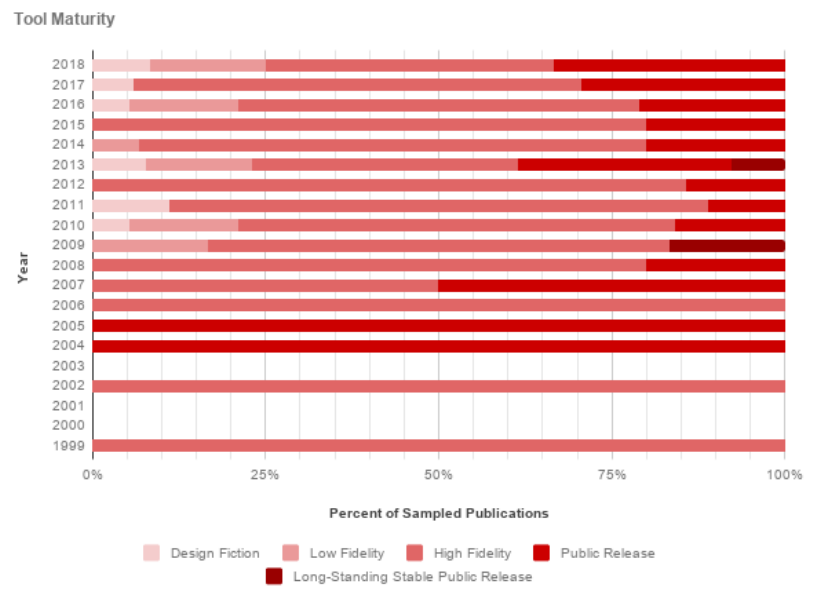

Figure 3: Level of Complexity of CSTs sampled. 


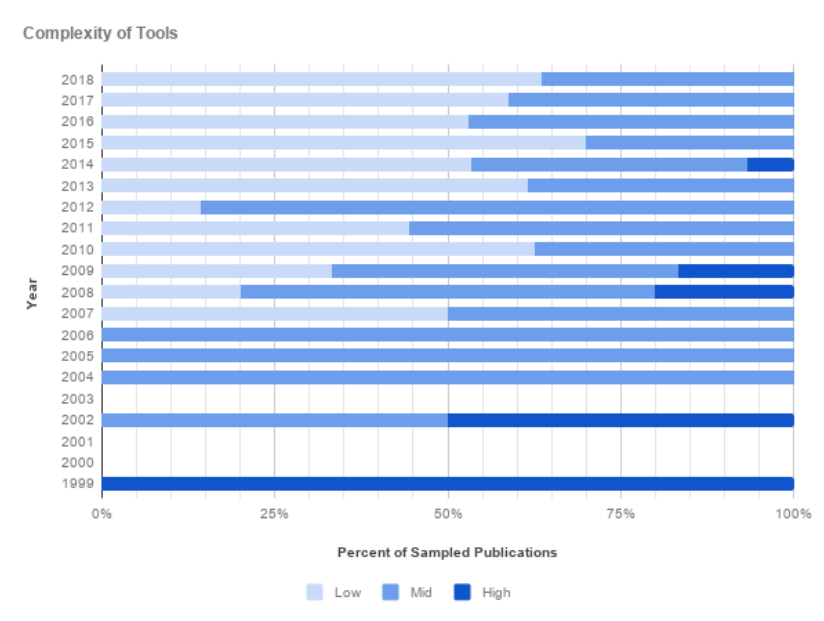

Figure 4: Level of Maturity of CSTs sampled.

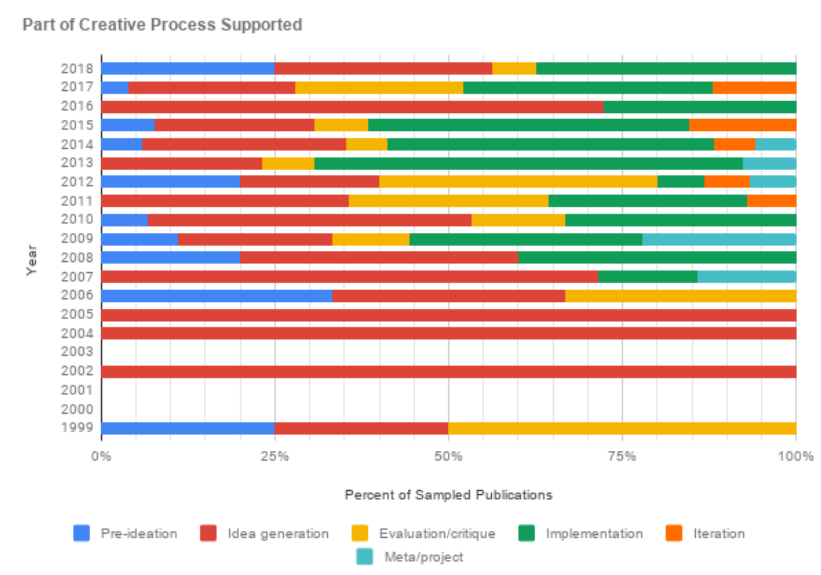

Figure 5: Parts of creative process supported by sampled CSTs.

devices that helps tourists create and edit videos of their holidays. Many CSTs are developed to the point of being publicly released (23\%, 33 publications). Low fidelity prototypes, e.g., paper or wizard-of-oz mock-ups, represent a smaller section of our sample ( $8 \%, 12$ publications). Fewer CSTs are presented as design fiction or a description of a possible tool and its use and impact, accounting for $4 \%$ (6 publications). Only 2 CSTs in our sample exist as long-standing, stable public releases (1\%): Sensecam [106] and StoryKit [16].

\section{Part of Creative Process Supported}

Idea generation or ideation is the most commonly supported creative process in our sample, comprising $45 \%$ of the publications, as shown in Figure 5. A tool that exemplifies ideation support is IdeaExpander, which, in a collaborative brainstorming setting, introduces sources of cultural and conceptual diversity in order to trigger additional ideas $[173,174]$. The second most common process supported is implementation or realization of the creative outcome ( $41 \%, 58$ publications). Examples include Drawing Apprentice [38], which facilitates collaborative digital sketching with the intention of improving artistic skills. Evaluating or critiquing either ideas or concepts is the third most commonly supported process at $18 \%$ of our sample (26 publications), e.g., the Choreographer's Notebook [161]. Tools that support problem identification accounted for a smaller portion of the publications $(10 \%, 15$ publications), e.g., MOB [72], followed by those that support iteration (6\%, 8 publications) e.g., MetaMorphe [168], or the management of the project or process ( $4 \%, 8$ publications), e.g., Pipeline [110].

\section{Target Audience}

Level of Expertise of Target Audience. When the audience or user group of the CST is specified, many of the tools presented are geared towards experts (33\%, 47 publications), followed by novices (17\%, 24 publications). These specific domains are most often children or designers (both vague categories).

Target Audience of CSTs. A thorough count of each target audience in the publications is difficult to accomplish, as the terminology varies from paper to paper. Therefore, we identify the most common occurring disciplines in our sample. Most CSTs in our sample are intended for designers, which includes designers, graphic designers, game designers, makers/designers, and user interface designers (28 publications).

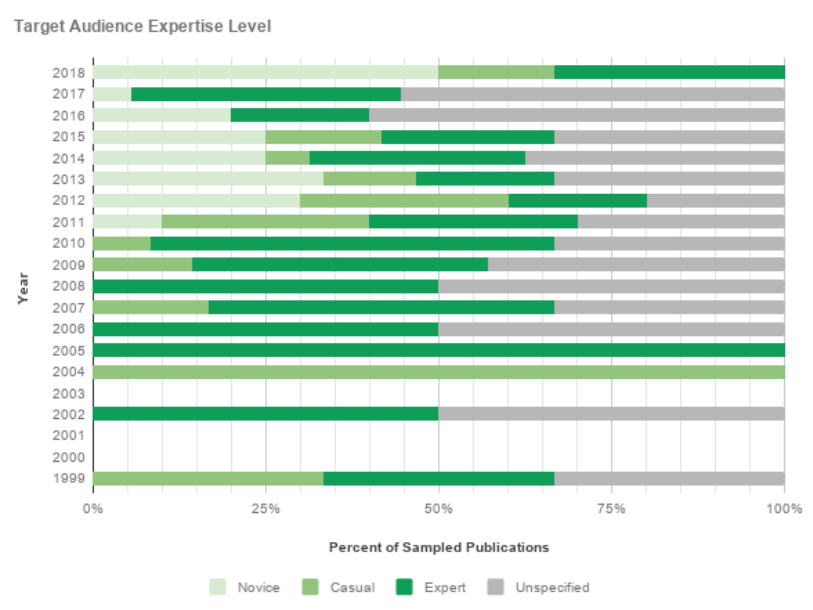

Figure 6: Level of expertise of target audience. 


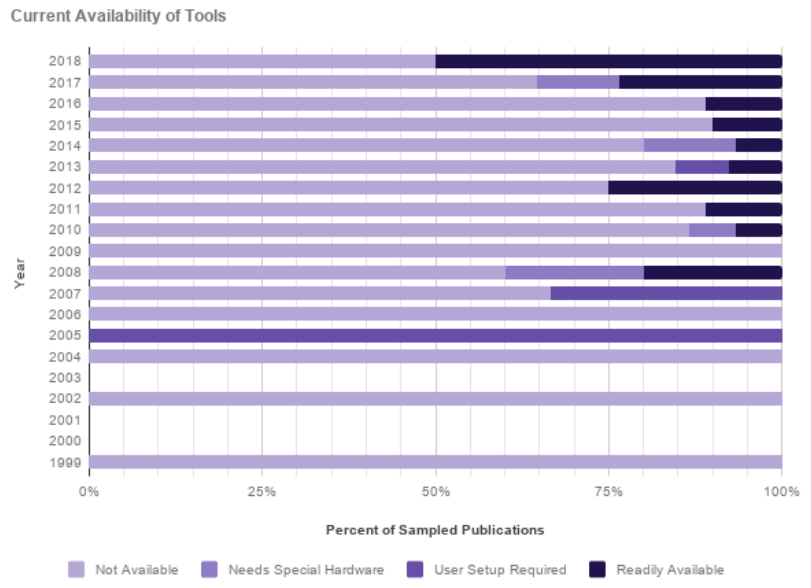

Figure 7: Availability of CSTs sampled.

This is followed by CSTs for children or teenagers (18 publications), musicians or composers (10 publications), artists, including painters, filmmakers, and illustrators (7 publications), researchers (6 publications), writers or journalists (4 publications), and choreographers (3 publications). Although several other groups were identified in our sample, they are not mentioned here, as each is only represented by one publication. These details are available in our supplementary material.

\section{Current Availability of Tools}

Most of the CSTs reviewed here are currently unavailable or inaccessible to the public (76\%, 109 publications), meaning that the URL for the tool provided in the paper returned a 404 error and/or a simple Google search returned no results. A small percentage of our sample is currently available to the public $(13 \%, 19$ publications). Fewer of the sampled CSTs $(4 \%$, 6 publications) are available, but require setting up special hardware, and 3\% (4 publications) can be accessed with some overhead, for example, by forking on GitHub, e.g., Bridge, combInformation, and Pipeline [47, 96, 110].

\section{DEVELOPMENTS IN THE FIELD OF CSTS}

In light of our results, we point towards possible trends and developments in CST research over the past twenty years. Although it is difficult to see concrete trends in much of our data, three trends do stand out. We first discuss the developments in areas with unclear trends.

Maturity. In the earlier years of our sampled publications, high-fidelity prototype CSTs account for a large portion of published work between 1999 and 2008 (between 80-100\%), although there is an unstable trend in their numbers over time (41.7\% in 2018). Low-fidelity prototype CSTs began appearing in 2009 and remain consistent at around 17\% of publications per year, with the exception or 2012 and 2015. There is a limited presence of tools presented as design fiction over time (5-10\%), which began appearing in 2011. Very few CSTs are long-standing public releases, with no distinguishable trend (17\% in 2009 and $7 \%$ in 2013).

Part of process supported. From 1999 until 2005, only preideation, idea generation and evaluation/critique tools are present in our sample, with only idea generation tools present in 2004 and 2005.

The number of pre-ideation tools shows no clear trend over time. Idea generation has stable representation as it occurs in every year of our sample, and from 2006 onwards accounts for between $20-40 \%$ of publications each year. Evaluation and critique CSTs have an unstable trend and are well-represented in some years, but completely absent in 2002, 2004, 2005, 2007, 2008 and 2016. No implementation tools published before 2007 occurred in our sample. They otherwise have consistent representation at around $40 \%$, with the exception of 2007, 2012 and 2013. Tools for iteration only appear after 2011, and following this, have consistent, but small representation (between 7-15\%), with the exception of 2016 and 2018 when they are completely absent. Meta-level tools, such as those meant for creative project management, occur only sporadically in our sample, and in the years that they are represented, they account for $20 \%$ or less.

Devices. Tools intended for use on personal computers or laptops remain consistent, which is likely due to many of them existing as web or browser-based applications. Trends in other types of devices are difficult to pinpoint in our sample, however, we can speculate that the low representation of CSTs intended for use on smartphones and tablets is due to constant updates and new releases of hardware.

Complexity. Our results show a trend of decrease in highcomplexity CSTs over time, being present in the literature in 1999 (100\%), 2002 (50\%), 2008 (20\%), 2009 (17\%) and 2014 (7\%). However, low-complexity CSTs have shown an increase in representation since 2007 . Medium-complexity tools maintain consistent representation in our sampling over time.

Availability. Many of the CSTs published are no longer available, meaning that the URL specified in the paper is currently, at the time of writing, returning a 404-error message. We found that the likelihood of this occurring increased proportionally to the age of the tool. Conversely, newer tools are more likely to be readily available online. We postulate that these findings can be explained by the known fact that for research labs, maintaining an online project repository can be difficult, especially if a CST was developed by a PhD student who has since graduated. Additionally, software deprecates over time, and it is possible that older CSTs are no longer compatible with current technology. 
Expertise. Although clear trends are difficult to distinguish in our sample of expertise level of the intended audience of the CSTs, we see a marked increase in the number of CSTs intended for novice users since 2011.

\section{DISCUSSION}

In addition to examining the trends and developments for each of the categories over time, a number of salient points stood out in the process of coding and analysing the corpus. These concern the ways in which CSTs were evaluated, the ways in which insights from creativity research to enrich the study and understanding of CSTs to a large extent are lacking from the surveyed contributions, the potentials and limitations of the focus on simple CSTs for novice users, and the lack of a consensus definition of CSTs.

\section{The Evaluation of CSTs}

One of the categories that sparked most discussion during and after the coding and analysis of our corpus was the evaluation of CSTs. Despite receiving more revisions, iterations, and discussions than any other part of the coding scheme, we felt that within the scope of this paper a thorough treatment of the evaluation of CSTs is not feasible. While HCI researchers have made inroads towards a standardized evaluation method for CSTs, most notably the Creativity Support Index $[21,22]$, we observed a wide range of efforts to validate the tools developed by researchers, reflecting the whole breadth of HCI evaluation techniques. Similarly, the criteria ranged from traditional creativity traits such as flexibility and fluency to classic usability principles.

We argue that those observations, in particular the tension between evaluating for the application domain (creativity) as well as the domain the research is being published in (HCI), is a side effect of the interdisciplinary nature of our field. This is not a novel observation, but rather a frequently discussed topic in the CHI community, as Special Interest Groups have attempted to engage with the intricate problem of evaluating research that goes beyond usability $[92,139]$. One potential avenue for future research is to seek inspiration in those efforts from other areas in the field of HCI. Three of the most recent examples are a survey of evaluation strategies for prototyping toolkits [104], a recipe for evaluating sustainability in HCI [138], and a triangulation of different evaluation methods [132]. Considering this ongoing discussion in the $\mathrm{CHI}$ community and following our analysis of the evaluation codes, we find a more meticulous approach is needed, and we issue a call to action for the $\mathrm{CHI}$ community to contribute to this topic. As a preliminary takeaway from our initial analysis we emphasize that the diversity of CSTs calls for a toolbox of various methods to evaluate CSTs rather than a one-size-fits-all approach.

\section{Reflection on CSTs in the Light of Creativity Research}

Since Guilford's pathbreaking psychometrics studies several decades ago, divergent thinking has enjoyed special attention in modern-day creativity research to an extent that there has been a tendency to equate creativity to divergent thinking $[144,148]$. As opposed to convergent thinking, which involves narrowing down possibilities and selecting the (presumed best) answer to a creative problem, divergent thinking is essentially about coming up with new ideas and unexpected solutions in a creative process. Rather than seeing divergent and convergent thinking as two compartmentalized types of thinking, it may be more expedient to see them as two ends of a cognitive continuum [45]. On this basis, it is interesting to see (Figure 5) how the diversity of CSTs has increased in the selected time span. In 2002, 2004, and 2005, all sampled publications focus specifically on the ideation part of the creative process, while, from 2006 onward, the publications gradually encompass more and more phases, whose relative distributions in the sample vary across the years. In this way, the development of CSTs contributed by the CHI community shows, in very condensed form, the same development that more established creativity research has undergone over several decades; that is, from a heavily pronounced focus on divergent thinking to a more holistic understanding of the creative process per se and the awareness that it is relevant to underpin (much) more than ideation through research and technological advancements.

Insofar as creativity is often construed as 'novel and useful' or 'original and appropriate' [146], the implementation part of the creative process is not always prioritized highly in creativity research. The most important criterion is to establish the social context in which the creative process and the creative product are situated [135]. Looking at Figure 5 , it is evident that the implementation phase is generally well-represented in the sampled publications. We speculate that this may be explained by the strong ties between HCI and the practice of design in which implementation is vital (see e.g., [8]); a point that seems further plausible given that most of the CSTs in the sample are intended for designers.

Furthermore, it is notable that, as depicted by Figure 6, many of the sampled publications $(\sim 38 \%)$ do not in their research methodology take into account the level of creative experience or expertise of the target audience of the CST being presented. This runs counter to creativity research in which much critical attention is given to the specific level of expertise among the relevant users or participants featured in a given study. One example is the so-called ' 10,000 hours rule' study by Ericsson et al. [44] (which has since been criticized, see e.g. [77]) and Weisberg's work on experts and geniuses [177]. The lack of attention to creative experience 
and/or expertise in the sampled publications further differs from much design research, e.g., Cross' [34] studies of expert designers, and, more recently, studies of analogical reasoning among novice and expert designers [131]. This underlines that while design research-and to a large extent creativity research-focuses on practical use of tools for supporting creativity, the same cannot be said about the sampled publications and their availability for practitioners. Often, the CSTs never leave the HCI labs in which they were created.

\section{Potentials and Limitations of HCI Research on Simple CSTs for Novice Users}

Our survey points to both potentials and limitations in the current state of HCI research on CSTs in relation to the use of digital tools in creative practice outside of research labs. If we combine the findings in terms of types of target audience and the complexity of the CSTs, we find a strong tendency towards developing simple tools for novice or casual users. This may well be the best fitting approach in each individual case. It may in some cases also match the wider uptake of simple CSTs in the wider public, such as basic photo-editing apps. However, considered in a wider perspective, it indicates that there are forms of creative practice that $\mathrm{HCI}$ research at this point only sparsely addresses. A particularly salient point concerns skillful creative practitioners' use of tools. From e.g. Kaufman and Beghetto's [91] influential work in creativity research on different forms of creative activities, we know that creative professionals typically develop so-called 'Pro-c skills,' "the developmental and effortful progression that represents professional-level expertise in any creative area" (p. 1), which distinguish them from novices and entail a great investment in time and effort to develop. This is supported by studies in design research, showing that designers' development of competence lies in a mastery of tools and an understanding of their potentials and limitations in a variety of situations that they may encounter in different design situations [58]. Also, many creative professionals use rather complex CSTs as core components in their work practice. Consider for instance software such as Adobe Photoshop for graphic designers, Final Cut for video producers, or Ableton Live for musicians; all are highly complex tools that require a significant investment in time to master, but also offer possibilities that simpler tools lack. We therefore see an obvious, untapped potential for HCI research on CSTs to extend into studies of more complex systems employed by expert users. We speculate that the large number of publications that present us with simple CSTs rather than complex ones may in part be a result of the general state of research in $\mathrm{HCI}$, in which there is a) a marked interest in technological novelty, and b) the requirements for in-depth analysis and evaluation prompt a focus on detailed studies of particular features or components of a system. Likewise, it is in many cases much more difficult to recruit expert practitioners than novices.

\section{Towards a Definition of Creativity Support Tools}

While it seems clear that "The goal of designing creativity support tools is to make more people more creative more often (...)" [154], it is less obvious what constitutes a CST, even on the basis of this thorough review of HCI research contributions that specifically present and discuss them. This lack of a consensus definition may be beneficial, for instance by keeping the scope of research open as new technologies emerge, and as digital technologies are employed in more and more forms of creative practice. On the other hand, a more precise account of what constitutes a CST may contribute to a higher level of conceptual clarity in the discussions of the role and nature of CSTs, and acts as a stepping stone towards building a more concise and mature vocabulary in the subfield. Based on our survey, a tentative synthesis definition could be as follows:

A Creativity Support Tool runs on one or more digital systems, encompasses one or more creativity-focused features, and is employed to positively influence users of varying expertise in one or more distinct phases of the creative process.

In our view, however, this definition may be so broad that it bears little meaning. It indicates to us that rather than develop a one-size-fits-all definition, a more productive way forward might be to develop more specific, contextualized definitions that address particular subsets of CSTs. These subsets could address, for instance, particular types of user groups, forms of interfaces, complexity, or phases of a creative process. We will not attempt to further define and delimit these proposed subsets of CSTs here. Firstly, because the data, in our view, is not be extensive enough to warrant it. As mentioned, there is a strong emphasis in the surveyed publications on simple CSTs for novice users, whereas there are potential uses of CSTs that are entirely lacking or only sparsely covered. Secondly, because we propose that this work also consider insights and definitions of creative processes and dynamics from state-of-the-art creativity research, which is a research trajectory that lies beyond the scope of this paper. This being said, we find this an avenue for future research that could greatly add to the development of HCI-based research into CSTs, and, moreover, help bridge the divide between HCI and creativity research.

\section{CONCLUSION}

The CHI community has seen a growing interest in developing Creativity Support Tools (CSTs) in the past twenty-five years, and this research venture has been identified as a socalled "grand challenge" for Human-Computer Interaction [156]. As would be expected by such an increase of CSTs available, the diversity of tools available has also grown. We 
now see tools intended for a wide variety of uses, varying in complexity from a simple tool with one useful function to an entire suite of tools. For a newcomer to this area of research, it could be a daunting task to get a sense of its history and trajectory. Through identifying a corpus of 143 novel CST contributions from the $\mathrm{CHI}$ community and examining them through the lens of creativity research, we have provided a preliminary overview of the growing landscape of creativity support tools in HCI.

\section{ACKNOWLEDGEMENTS}

We thank our reviewers for the appreciation of our work and their helpful and constructive suggestions to improve this paper. This research has been funded by The Velux Foundations grant: Digital Tools in Collaborative Creativity (grant no. 00013140), and the Aarhus University Research Foundation grant: Creative Tools.

\section{REFERENCES}

[1] Steven Abrams, Ralph Bellofatto, Robert Fuhrer, Daniel Oppenheim, James Wright, Richard Boulanger, Neil Leonard, David Mash, Michael Rendish, and Joe Smith. 2002. QSketcher: An Environment for Composing Music for Film. In Proceedings of the 4th Conference on Creativity \& Cognition. ACM, New York, NY, USA, 157-164. https://doi.org/10.1145/581710.581734

[2] Philip van Allen, Joshua McVeigh-Schultz, Brooklyn Brown, Hye Mi Kim, and Daniel Lara. 2013. AniThings: Animism and Heterogeneous Multiplicity. In CHI '13 Extended Abstracts on Human Factors in Computing Systems. ACM, New York, NY, USA, 2247-2256. https://doi.org/10.1145/2468356.2468746

[3] Patrícia Alves-Oliveira, Patrícia Arriaga, Ana Paiva, and Guy Hoffman. 2017. YOLO, a Robot for Creativity: A Co-Design Study with Children. In Proceedings of the 2017 Conference on Interaction Design and Children - IDC '17. ACM Press, Stanford, California, USA, 423-429. https://doi.org/10.1145/3078072.3084304

[4] Teresa M Amabile. 1983. The social psychology of creativity: A componential conceptualization. Fournal of personality and social psychology 45, 2 (1983), 357.

[5] Teresa M Amabile. 1996. Creativity in context: Update to "The social psychology of creativity" (2 ed.). Westview Press, Boulder, CO.

[6] Teresa M Amabile. 2013. Componential theory of creativity. In Encyclopedia of management theory. SAGE, Thousand Oaks, Calif, 135-140.

[7] Salvatore Andolina, Hendrik Schneider, Joel Chan, Khalil Klouche, Giulio Jacucci, and Steven Dow. 2017. Crowdboard: Augmenting In-Person Idea Generation with Real-Time Crowds. In Proceedings of the 2017 ACM SIGCHI Conference on Creativity and Cognition - C\&C '17. ACM Press, Singapore, Singapore, 106-118. https://doi.org/10. $1145 / 3059454.3059477$

[8] Hedda Haugen Askland, Michael Ostwald, and Anthony Williams. 2010. Changing Conceptualisations of Creativity in Design. In Proceedings of the 1st DESIRE Network Conference on Creativity and Innovation in Design (DESIRE '10). Desire Network, Lancaster, UK, UK, 4-11. http://dl.acm.org/citation.cfm?id=1854969.1854975

[9] Maryam Azh, Shengdong Zhao, and Sriram Subramanian. 2016. Investigating Expressive Tactile Interaction Design in Artistic Graphical Representations. ACM Trans. Comput.-Hum. Interact. 23, 5 (Oct. 2016), 32:1-32:47. https://doi.org/10.1145/2957756
[10] Patti Bao, Elizabeth Gerber, Darren Gergle, and David Hoffman. 2010. Momentum: Getting and Staying on Topic During a Brainstorm. In Proceedings of the SIGCHI Conference on Human Factors in Computing Systems. ACM, New York, NY, USA, 1233-1236. https://doi.org/10. 1145/1753326.1753511

[11] Gabriel Barata, Sandra Gama, Manuel J. Fonseca, and Daniel Gonçalves. 2013. Improving Student Creativity with Gamification and Virtual Worlds. In Proceedings of the First International Conference on Gameful Design, Research, and Applications. ACM, New York, NY, USA, 95-98. https://doi.org/10.1145/2583008.2583023

[12] Eric P.S. Baumer, Jordan Sinclair, and Bill Tomlinson. 2010. America is Like Metamucil: Fostering Critical and Creative Thinking About Metaphor in Political Blogs. In Proceedings of the SIGCHI Conference on Human Factors in Computing Systems. ACM, New York, NY, USA, 1437-1446. https://doi.org/10.1145/1753326.1753541

[13] Tilde Bekker, Janienke Sturm, and Berry Eggen. 2010. Designing Playful Interactions for Social Interaction and Physical Play. Personal Ubiquitous Comput. 14, 5 (July 2010), 385-396. https://doi.org/10. 1007/s00779-009-0264-1

[14] Luca Benedetti, Holger Winnemöller, Massimiliano Corsini, and Roberto Scopigno. 2014. Painting with Bob: Assisted Creativity for Novices. In Proceedings of the 27th Annual ACM Symposium on User Interface Software and Technology. ACM, New York, NY, USA, 419-428. https://doi.org/10.1145/2642918.2647415

[15] Ben Bengler and Nick Bryan-Kinns. 2013. Designing Collaborative Musical Experiences for Broad Audiences. In Proceedings of the 9th ACM Conference on Creativity \& Cognition. ACM, New York, NY, USA, 234-242. https://doi.org/10.1145/2466627.2466633

[16] Elizabeth Bonsignore, Alexander J. Quinn, Allison Druin, and Benjamin B. Bederson. 2013. Sharing Stories "in the Wild": A Mobile Storytelling Case Study Using StoryKit. ACM Trans. Comput.-Hum. Interact. 20, 3 (July 2013), 18:1-18:38. https://doi.org/10.1145/2491500.2491506

[17] N. Bryan-Kinns. 2004. Daisyphone: The Design and Impact of a Novel Environment for Remote Group Music Improvisation. In Proceedings of the 5th Conference on Designing Interactive Systems: Processes, Practices, Methods, and Techniques. ACM, New York, NY, USA, 135-144. https://doi.org/10.1145/1013115.1013135

[18] Nick Bryan-Kinns, Patrick G. T. Healey, and Joe Leach. 2007. Exploring Mutual Engagement in Creative Collaborations. In Proceedings of the 6th ACM SIGCHI Conference on Creativity \& Cognition. ACM, New York, NY, USA, 223-232. https://doi.org/10.1145/1254960.1254991

[19] Linda Candy and Koichi Hori. 2003. The Digital Muse: HCI in Support of Creativity: "Creativity and Cognition" Comes of Age: Towards a New Discipline. interactions 10, 4 (July 2003), 44-54. https://doi.org/ 10.1145/838830.838833

[20] Xiang Cao, Siân E. Lindley, John Helmes, and Abigail Sellen. 2010. Telling the Whole Story: Anticipation, Inspiration and Reputation in a Field Deployment of TellTable. In Proceedings of the 2010 ACM Conference on Computer Supported Cooperative Work. ACM, New York, NY, USA, 251-260. https://doi.org/10.1145/1718918.1718967

[21] Erin A. Carroll and Celine Latulipe. 2009. The Creativity Support Index. In CHI '09 Extended Abstracts on Human Factors in Computing Systems (CHI EA '09). ACM, New York, NY, USA, 4009-4014. https: //doi.org/10.1145/1520340.1520609

[22] Erin A. Carroll, Celine Latulipe, Richard Fung, and Michael Terry. 2009. Creativity Factor Evaluation: Towards a Standardized Survey Metric for Creativity Support. In Proceedings of the Seventh ACM Conference on Creativity and Cognition. ACM, New York, NY, USA, 127-136. https://doi.org/10.1145/1640233.1640255

[23] John B Carroll. 1968. Reviews: Guilford, J.P. "The Nature of Human Intelligence". American Educational Research fournal 5, 2 (1968), 249256. 
[24] Alejandro Catala, Javier Jaen, Betsy van Dijk, and Sergi Jordà. 2012 Exploring Tabletops As an Effective Tool to Foster Creativity Traits. In Proceedings of the Sixth International Conference on Tangible, Embedded and Embodied Interaction. ACM, New York, NY, USA, 143-150. https://doi.org/10.1145/2148131.2148163

[25] Joel Chan, Steven Dang, and Steven P Dow. 2016. Improving Crowd Innovation with Expert Facilitation. In Proceedings of the 19th ACM Conference on Computer-Supported Cooperative Work \& Social Computing - CSCW'16. ACM Press, San Francisco, California, USA, 1221-1233. https://doi.org/10.1145/2818048.2820023

[26] Siddhartha Chaudhuri and Vladlen Koltun. 2010. Data-driven Suggestions for Creativity Support in 3D Modeling. In ACM SIGGRAPH Asia 2010 Papers. ACM, New York, NY, USA, 183:1-183:10. https: //doi.org/10.1145/1866158.1866205

[27] Erin Cherry and Celine Latulipe. 2014. Quantifying the Creativity Support of Digital Tools Through the Creativity Support Index. ACM Trans. Comput.-Hum. Interact. 21, 4 (June 2014), 21:1-21:25. https: //doi.org/10.1145/2617588

[28] Sharon Lynn Chu Yew Yee, Francis K.H. Quek, and Lin Xiao. 2011. Studying Medium Effects on Children's Creative Processes. In Proceedings of the 8th ACM Conference on Creativity and Cognition. ACM, New York, NY, USA, 3-12. https://doi.org/10.1145/2069618.2069622

[29] Marianela Ciolfi Felice, Sarah Fdili Alaoui, and Wendy E. Mackay. 2018. Knotation: Exploring and Documenting Choreographic Processes. In Proceedings of the 2018 CHI Conference on Human Factors in Computing Systems (CHI '18). ACM, New York, NY, USA, 448:1-448:12. https://doi.org/10.1145/3173574.3174022

[30] Elizabeth Clark, Anne Spencer Ross, Chenhao Tan, Yangfeng Ji, and Noah A. Smith. 2018. Creative Writing with a Machine in the Loop: Case Studies on Slogans and Stories. In Proceedings of the 2018 Conference on Human Information Interaction\&Retrieval - IUI '18. ACM Press, Tokyo, Japan, 329-340. https://doi.org/10.1145/3172944.3172983

[31] Simon Colton, Michel F. Valstar, and Maja Pantic. 2008. Emotionally Aware Automated Portrait Painting. In Proceedings of the 3rd International Conference on Digital Interactive Media in Entertainment and Arts. ACM, New York, NY, USA, 304-311. https: //doi.org/10.1145/1413634.1413690

[32] Tim Coughlan and Peter Johnson. 2006. Interaction in Creative Tasks. In Proceedings of the SIGCHI Conference on Human Factors in Computing Systems. ACM, New York, NY, USA, 531-540. https: //doi.org/10.1145/1124772.1124854

[33] Tim Coughlan and Peter Johnson. 2009. Understanding Productive, Structural and Longitudinal Interactions in the Design of Tools for Creative Activities. In Proceedings of the Seventh ACM Conference on Creativity and Cognition. ACM, New York, NY, USA, 155-164. https://doi.org/10.1145/1640233.1640258

[34] Nigel Cross. 2004. Expertise in design: an overview. Design Studies 25, 5 (Sept. 2004), 427-441. https://doi.org/10.1016/j.destud.2004.06.002

[35] Sayamindu Dasgupta, William Hale, Andrés Monroy-Hernández, and Benjamin Mako Hill. 2016. Remixing as a Pathway to Computational Thinking. In Proceedings of the 19th ACM Conference on ComputerSupported Cooperative Work \& Social Computing - CSCW '16. ACM Press, San Francisco, California, USA, 1436-1447. https://doi.org/10. $1145 / 2818048.2819984$

[36] Sayamindu Dasgupta and Benjamin Mako Hill. 2017. Scratch Community Blocks: Supporting Children as Data Scientists. In Proceedings of the 2017 CHI Conference on Human Factors in Computing Systems - CHI '17. ACM Press, Denver, Colorado, USA, 3620-3631. https://doi.org/10.1145/3025453.3025847

[37] Matthew E. P. Davies, Philippe Hamel, Kazuyoshi Yoshii, and Masataka Goto. 2014. AutoMashUpper: Automatic Creation of Multi-song Music Mashups. IEEE/ACM Trans. Audio, Speech and Lang. Proc. 22, 12
(Dec. 2014), 1726-1737. https://doi.org/10.1109/TASLP.2014.2347135

[38] Nicholas Davis, Chih-PIn Hsiao, Kunwar Yashraj Singh, Lisa Li, Sanat Moningi, and Brian Magerko. 2015. Drawing Apprentice: An Enactive Co-Creative Agent for Artistic Collaboration. In Proceedings of the 2015 ACM SIGCHI Conference on Creativity and Cognition. ACM, New York, NY, USA, 185-186. https://doi.org/10.1145/2757226.2764555

[39] Nicholas Davis, Chih-PIn Hsiao, Kunwar Yashraj Singh, Lisa Li, and Brian Magerko. 2016. Empirically Studying Participatory SenseMaking in Abstract Drawing with a Co-Creative Cognitive Agent. In Proceedings of the 21st International Conference on Intelligent User Interfaces - IUI '16. ACM Press, Sonoma, California, USA, 196-207. https://doi.org/10.1145/2856767.2856795

[40] Nicholas Davis, Alexander Zook, Brian O’Neill, Brandon Headrick, Mark Riedl, Ashton Grosz, and Michael Nitsche. 2013. Creativity Support for Novice Digital Filmmaking. In Proceedings of the SIGCHI Conference on Human Factors in Computing Systems. ACM, New York, NY, USA, 651-660. https://doi.org/10.1145/2470654.2470747

[41] Jelle van Dijk, Jirka van der Roest, Remko van der Lugt, and Kees C.J. Overbeeke. 2011. NOOT: A Tool for Sharing Moments of Reflection During Creative Meetings. In Proceedings of the 8th ACM Conference on Creativity and Cognition. ACM, New York, NY, USA, 157-164. https://doi.org/10.1145/2069618.2069646

[42] Carl DiSalvo, Marti Louw, Julina Coupland, and MaryAnn Steiner. 2009. Local Issues, Local Uses: Tools for Robotics and Sensing in Community Contexts. In Proceedings of the Seventh ACM Conference on Creativity and Cognition. ACM, New York, NY, USA, 245-254. https://doi.org/10.1145/1640233.1640271

[43] Shelly Engelman, Brian Magerko, Tom McKlin, Morgan Miller, Doug Edwards, and Jason Freeman. 2017. Creativity in Authentic STEAM Education with EarSketch. In Proceedings of the 2017 ACM SIGCSE Technical Symposium on Computer Science Education - SIGCSE ' 17. ACM Press, Seattle, Washington, USA, 183-188. https://doi.org/10. 1145/3017680.3017763

[44] K. Anders Ericsson, Ralf T. Krampe, and Clemens Tesch-Römer. 1993. The role of deliberate practice in the acquisition of expert performance. Psychological Review 100, 3 (1993), 363-406. https: //doi.org/10.1037/0033-295X.100.3.363

[45] H. J. Eysenck. 2003. Creativity, personality and the convergentdivergent continuum. In Critical creative processes. Hampton Press, Cresskill, NJ, US, 95-114.

[46] Umer Farooq, John M. Carroll, and Craig H. Ganoe. 2005. Supporting Creativity in Distributed Scientific Communities. In Proceedings of the 2005 International ACM SIGGROUP Conference on Supporting Group Work. ACM, New York, NY, USA, 217-226. https://doi.org/10.1145/ 1099203.1099242

[47] Umer Farooq, John M. Carroll, and Craig H. Ganoe. 2007. Supporting Creativity with Awareness in Distributed Collaboration. In Proceedings of the 2007 International ACM Conference on Supporting Group Work. ACM, New York, NY, USA, 31-40. https: //doi.org/10.1145/1316624.1316630

[48] Ronald A Finke, Thomas B Ward, and Steven M Smith. 1992. Creative cognition: Theory, research, and applications. Bradford Books/MIT Press, Cambridge, MA.

[49] Gerhard Fischer. 1999. Symmetry of Igorance, Social Creativity, and Meta-design. In Proceedings of the 3rd Conference on Creativity \& Cognition. ACM, New York, NY, USA, 116-123. https://doi.org/10. $1145 / 317561.317582$

[50] Gerhard Fischer. 2004. Social Creativity: Turning Barriers into Opportunities for Collaborative Design. In Proceedings of the Eighth Conference on Participatory Design: Artful Integration: Interweaving Media, Materials and Practices - Volume 1. ACM, New York, NY, USA, 152-161. https://doi.org/10.1145/1011870.1011889 
[51] Jonas Frich, Michael Mose Biskjaer, and Peter Dalsgaard. 2018. Why $\mathrm{HCI}$ and Creativity Research Must Collaborate to Develop New Creativity Support Tools. In Proceedings of the Technology, Mind, and Society. ACM Press, Washington, DC, USA, 1-6. https://doi.org/10. 1145/3183654.3183678

[52] Jonas Frich, Michael Mose Biskjaer, and Peter Dalsgaard. 2018. Twenty Years of Creativity Research in Human-Computer Interaction: Current State and Future Directions. In Proceedings of the 2018 Designing Interactive Systems Conference (DIS '18). ACM, New York, NY, USA, 1235-1257. https://doi.org/10.1145/3196709.3196732

[53] Batya Friedman and David Hendry. 2012. The Envisioning Cards: A Toolkit for Catalyzing Humanistic and Technical Imaginations. In Proceedings of the SIGCHI Conference on Human Factors in Computing Systems. ACM, New York, NY, USA, 1145-1148. https://doi.org/10. $1145 / 2207676.2208562$

[54] Quentin Galvane, Marc Christie, Chrsitophe Lino, and Rémi Ronfard. 2015. Camera-on-rails: Automated Computation of Constrained Camera Paths. In Proceedings of the 8th ACM SIGGRAPH Conference on Motion in Games. ACM, New York, NY, USA, 151-157. https: //doi.org/10.1145/2822013.2822025

[55] Jérémie Garcia, Theophanis Tsandilas, Carlos Agon, and Wendy E. Mackay. 2014. Structured Observation with Polyphony: A Multifaceted Tool for Studying Music Composition. In Proceedings of the 2014 Conference on Designing Interactive Systems. ACM, New York, NY, USA, 199-208. https://doi.org/10.1145/2598510.2598512

[56] Howard Gardner. 1988. Creativity: An interdisciplinary perspective. Creativity Research fournal 1, 1 (Dec. 1988), 8-26. https://doi.org/10. 1080/10400418809534284

[57] Lorenzo Gatti, Gozde Ozbal, Marco Guerini, Oliviero Stock, and Carlo Strapparava. 2016. Heady-Lines: A Creative Generator Of Newspaper Headlines. In Companion Publication of the 21st International Conference on Intelligent User Interfaces - IUI '16 Companion. ACM Press, Sonoma, California, USA, 79-83. https://doi.org/10.1145/2876456. 2879469

[58] Henrik Gedenryd. 1998. How designers work - making sense of authentic cognitive activities. Lund University Cognitive Studies 75 (1998). https://www.lunduniversity.lu.se/lup/publication/ d88efa51-c2f9-4551-a259-00bd36fe8d03

[59] Florian Geyer, Jochen Budzinski, and Harald Reiterer. 2012. IdeaVis: A Hybrid Workspace and Interactive Visualization for Paper-based Collaborative Sketching Sessions. In Proceedings of the 7th Nordic Conference on Human-Computer Interaction: Making Sense Through Design. ACM, New York, NY, USA, 331-340. https://doi.org/10.1145/ 2399016.2399069

[60] Florian Geyer, Hans-Christian Jetter, Ulrike Pfeil, and Harald Reiterer. 2010. Collaborative Sketching with Distributed Displays and Multimodal Interfaces. In ACM International Conference on Interactive Tabletops and Surfaces. ACM, New York, NY, USA, 259-260. https://doi.org/10.1145/1936652.1936705

[61] Florian Geyer, Ulrike Pfeil, Anita Höchtl, Jochen Budzinski, and Harald Reiterer. 2011. Designing Reality-based Interfaces for Creative Group Work. In Proceedings of the 8th ACM Conference on Creativity and Cognition. ACM, New York, NY, USA, 165-174. https: //doi.org/10.1145/2069618.2069647

[62] Karni Gilon, Joel Chan, Felicia Y. Ng, Hila Liifshitz-Assaf, Aniket Kittur, and Dafna Shahaf. 2018. Analogy Mining for Specific Design Needs. In Proceedings of the 2018 CHI Conference on Human Factors in Computing Systems - CHI '18. ACM Press, Montreal QC, Canada, 1-11. https://doi.org/10.1145/3173574.3173695

[63] Victor Girotto. 2016. Collective Creativity through a Micro-Tasks Crowdsourcing Approach. In Proceedings of the 19th ACM Conference on Computer Supported Cooperative Work and Social Computing Companion - CSCW'16 Companion. ACM Press, San Francisco, California,
USA, 143-146. https://doi.org/10.1145/2818052.2874356

[64] Victor Girotto, Erin Walker, and Winslow Burleson. 2017. The Effect of Peripheral Micro-tasks on Crowd Ideation. In Proceedings of the 2017 CHI Conference on Human Factors in Computing Systems - CHI '17. ACM Press, Denver, Colorado, USA, 1843-1854. https://doi.org/ $10.1145 / 3025453.3025464$

[65] Michael Golembewski and Mark Selby. 2010. Ideation Decks: A Cardbased Design Ideation Tool. In Proceedings of the 8th ACM Conference on Designing Interactive Systems. ACM, New York, NY, USA, 89-92. https://doi.org/10.1145/1858171.1858189

[66] Eric Gordon, Becky E. Michelson, and Jason Haas. 2016. @Stake: A Game to Facilitate the Process of Deliberative Democracy. In Proceedings of the 19th ACM Conference on Computer Supported Cooperative Work and Social Computing Companion - CSCW' 16 Companion. ACM Press, San Francisco, California, USA, 269-272. https://doi.org/10.1145/2818052.2869125

[67] Garth Griffin and Robert Jacob. 2013. Priming Creativity Through Improvisation on an Adaptive Musical Instrument. In Proceedings of the 9th ACM Conference on Creativity \& Cognition. ACM, New York, NY, USA, 146-155. https://doi.org/10.1145/2466627.2466630

[68] J. P. Guilford. 1950. Creativity. American Psychologist 5, 9 (1950), 444-454. https://doi.org/10.1037/h0063487

[69] Joy Paul Guilford. 1959. Three faces of intellect. American psychologist 14, 8 (1959), 469.

[70] Joy Paul Guilford. 1967. The nature of human intelligence. McGrawHill, New York.

[71] Magdalena Gärtner, Alexander Meschtscherjakov, Bernhard Maurer, David Wilfinger, and Manfred Tscheligi. 2014. "Dad, Stop Crashing My Car!": Making Use of Probing to Inspire the Design of Future In-Car Interfaces. In Proceedings of the 6th International Conference on Automotive User Interfaces and Interactive Vehicular Applications. ACM, New York, NY, USA, 27:1-27:8. https://doi.org/10.1145/2667317. 2667348

[72] Florian Güldenpfennig, Wolfgang Reitberger, and Geraldine Fitzpatrick. 2012. Capturing Rich Media Through Media Objects on Smartphones. In Proceedings of the 24th Australian Computer-Human Interaction Conference. ACM, New York, NY, USA, 180-183. https: //doi.org/10.1145/2414536.2414569

[73] Adam Haar Horowitz, Ishaan Grover, Pedro Reynolds-Cuéllar, Cynthia Breazeal, and Pattie Maes. 2018. Dormio: Interfacing with Dreams. In Extended Abstracts of the 2018 CHI Conference on Human Factors in Computing Systems (CHI EA '18). ACM, New York, NY, USA, alt10:1alt10:10. https://doi.org/10.1145/3170427.3188403

[74] Joshua Hailpern, Erik Hinterbichler, Caryn Leppert, Damon Cook, and Brian P. Bailey. 2007. TEAM STORM: Demonstrating an Interaction Model for Working with Multiple Ideas During Creative Group Work. In Proceedings of the 6th ACM SIGCHI Conference on Creativity \& Cognition. ACM, New York, NY, USA, 193-202. https: //doi.org/10.1145/1254960.1254987

[75] John Halloran, Eva Hornecker, Geraldine Fitzpatrick, Mark Weal, David Millard, Danius Michaelides, Don Cruickshank, and David De Roure. 2006. The Literacy Fieldtrip: Using UbiComp to Support Children's Creative Writing. In Proceedings of the 2006 Conference on Interaction Design and Children. ACM, New York, NY, USA, 17-24. https://doi.org/10.1145/1139073.1139083

[76] Megan K. Halpern, Jakob Tholander, Max Evjen, Stuart Davis, Andrew Ehrlich, Kyle Schustak, Eric P.S. Baumer, and Geri Gay. 2011. MoBoogie: Creative Expression Through Whole Body Musical Interaction. In Proceedings of the SIGCHI Conference on Human Factors in Computing Systems. ACM, New York, NY, USA, 557-560. https://doi.org/10.1145/1978942.1979020 
[77] David Z. Hambrick, Frederick L. Oswald, Erik M. Altmann, Elizabeth J. Meinz, Fernand Gobet, and Guillermo Campitelli. 2014. Deliberate practice: Is that all it takes to become an expert? Intelligence 45 (July 2014), 34-45. https://doi.org/10.1016/j.intell.2013.04.001

[78] Otmar Hilliges, Lucia Terrenghi, Sebastian Boring, David Kim, Hendrik Richter, and Andreas Butz. 2007. Designing for Collaborative Creative Problem Solving. In Proceedings of the 6th ACM SIGCHI Conference on Creativity \& Cognition. ACM, New York, NY, USA, 137-146. https://doi.org/10.1145/1254960.1254980

[79] Rania Hodhod and Brian Magerko. 2016. Closing the Cognitive Gap between Humans and Interactive Narrative Agents Using Shared Mental Models. In Proceedings of the 21st International Conference on Intelligent User Interfaces - IUI '16. ACM Press, Sonoma, California, USA, 135-146. https://doi.org/10.1145/2856767.2856774

[80] Eva Hornecker. 2010. Creative Idea Exploration Within the Structure of a Guiding Framework: The Card Brainstorming Game. In Proceedings of the Fourth International Conference on Tangible, Embedded, and Embodied Interaction. ACM, New York, NY, USA, 101-108. https://doi.org/10.1145/1709886.1709905

[81] Cheng-Zhi Anna Huang, David Duvenaud, and Krzysztof Z. Gajos. 2016. ChordRipple: Recommending Chords to Help Novice Composers Go Beyond the Ordinary. In Proceedings of the 21st International Conference on Intelligent User Interfaces - IUI '16. ACM Press, Sonoma, California, USA, 241-250. https://doi.org/10.1145/2856767.2856792

[82] Samuel Huron, Pauline Gourlet, Uta Hinrichs, Trevor Hogan, and Yvonne Jansen. 2017. Let's Get Physical: Promoting Data Physicalization in Workshop Formats. In Proceedings of the 2017 Conference on Designing Interactive Systems - DIS '17. ACM Press, Edinburgh, United Kingdom, 1409-1422. https://doi.org/10.1145/3064663.3064798

[83] Junko Ichino, Aura Pon, Ehud Sharlin, David Eagle, and Sheelagh Carpendale. 2014. Vuzik: The Effect of Large Gesture Interaction on Children's Creative Musical Expression. In Proceedings of the 26th Australian Computer-Human Interaction Conference on Designing Futures: The Future of Design. ACM, New York, NY, USA, 240-249. https://doi.org/10.1145/2686612.2686649

[84] Scott G Isaksen and Donald J Treffinger. 1985. Creative problem solving. The Basic Course. New York: Bearly Limited (1985).

[85] Scott G. Isaksen and Donald J. Treffinger. 2004. Celebrating 50 years of Reflective Practice: Versions of Creative Problem Solving. The fournal of Creative Behavior 38, 2 (June 2004), 75-101. https://doi. org/10.1002/j.2162-6057.2004.tb01234.x

[86] Sam Jacoby and Leah Buechley. 2013. Drawing the Electric: Storytelling with Conductive Ink. In Proceedings of the 12th International Conference on Interaction Design and Children. ACM, New York, NY, USA, 265-268. https://doi.org/10.1145/2485760.2485790

[87] Peter H. Kahn, Takayuki Kanda, Hiroshi Ishiguro, Brian T. Gill, Solace Shen, Jolina H. Ruckert, and Heather E. Gary. 2016. Human creativity can be facilitated through interacting with a social robot. In 2016 11th ACM/IEEE International Conference on Human-Robot Interaction (HRI). IEEE, Christchurch, New Zealand, 173-180. https://doi.org/10.1109/ HRI.2016.7451749

[88] Michael Karlesky and Katherine Isbister. 2014. Designing for the Physical Margins of Digital Workspaces: Fidget Widgets in Support of Productivity and Creativity. In Proceedings of the 8th International Conference on Tangible, Embedded and Embodied Interaction. ACM, New York, NY, USA, 13-20. https://doi.org/10.1145/2540930.2540978

[89] Jun Kato, Tomoyasu Nakano, and Masataka Goto. 2015. TextAlive: Integrated Design Environment for Kinetic Typography. In Proceedings of the 33rd Annual ACM Conference on Human Factors in Computing Systems. ACM, New York, NY, USA, 3403-3412. https://doi.org/10.1145/2702123.2702140

[90] Natsumi Kato, Hiroyuki Osone, Daitetsu Sato, Naoya Muramatsu, and Yoichi Ochiai. 2018. DeepWear: a Case Study of Collaborative
Design between Human and Artificial Intelligence. In Proceedings of the Twelfth International Conference on Tangible, Embedded, and Embodied Interaction - TEI '18. ACM Press, Stockholm, Sweden, 529536. https://doi.org/10.1145/3173225.3173302

[91] James C. Kaufman and Ronald A. Beghetto. 2009. Beyond big and little: The four c model of creativity. Review of General Psychology 13, 1 (2009), 1-12. https://doi.org/10.1037/a0013688

[92] Joseph 'Jofish' Kaye, Kirsten Boehner, Jarmo Laaksolahti, and Anna Stla ahl. 2007. Evaluating Experience-focused HCI. In CHI '07 Extended Abstracts on Human Factors in Computing Systems (CHI EA '07). ACM, New York, NY, USA, 2117-2120. https://doi.org/10.1145/ 1240866.1240962

[93] Rubaiat Habib Kazi, Kien Chuan Chua, Shengdong Zhao, Richard Davis, and Kok-Lim Low. 2011. SandCanvas: A Multi-touch Art Medium Inspired by Sand Animation. In Proceedings of the SIGCHI Conference on Human Factors in Computing Systems. ACM, New York, NY, USA, 1283-1292. https://doi.org/10.1145/1978942.1979133

[94] Andruid Kerne, Andrew Billingsley, Nic Lupfer, Rhema Linder, Yin Qu, Alyssa Valdez, Ajit Jain, Kade Keith, Matthew Carrasco, and Jorge Vanegas. 2017. Strategies of Free-Form Web Curation: Processes of Creative Engagement with Prior Work. In Proceedings of the 2017 ACM SIGCHI Conference on Creativity and Cognition - C\&C '17. ACM Press, Singapore, Singapore, 380-392. https://doi.org/10.1145/ 3059454.3059471

[95] Andruid Kerne, Eunyee Koh, Steven Smith, Hyun Choi, Ross Graeber, and Andrew Webb. 2007. Promoting Emergence in Information Discovery by Representing Collections with Composition. In Proceedings of the 6th ACM SIGCHI Conference on Creativity \& Cognition. ACM, New York, NY, USA, 117-126. https://doi.org/10.1145/1254960. 1254977

[96] Andruid Kerne, Eunyee Koh, Steven M. Smith, Andrew Webb, and Blake Dworaczyk. 2008. combinFormation: Mixed-initiative Composition of Image and Text Surrogates Promotes Information Discovery. ACM Trans. Inf. Syst. 27, 1 (Dec. 2008), 5:1-5:45. https: //doi.org/10.1145/1416950.1416955

[97] Andruid Kerne, Andrew M. Webb, Steven M. Smith, Rhema Linder, Nic Lupfer, Yin Qu, Jon Moeller, and Sashikanth Damaraju. 2014. Using Metrics of Curation to Evaluate Information-Based Ideation. ACM Trans. Comput.-Hum. Interact. 21, 3 (June 2014), 14:1-14:48. https://doi.org/10.1145/2591677

[98] Joy Kim, Maneesh Agrawala, and Michael S. Bernstein. 2017. Mosaic: Designing Online Creative Communities for Sharing Works-inProgress. In Proceedings of the 2017 ACM Conference on Computer Supported Cooperative Work and Social Computing - CSCW'17. ACM Press, Portland, Oregon, USA, 246-258. https://doi.org/10.1145/2998181. 2998195

[99] Joy Kim, Justin Cheng, and Michael S. Bernstein. 2014. Ensemble: Exploring Complementary Strengths of Leaders and Crowds in Creative Collaboration. In Proceedings of the 17th ACM Conference on Computer Supported Cooperative Work \& Social Computing. ACM, New York, NY, USA, 745-755. https://doi.org/10.1145/2531602.2531638

[100] Joy Kim, Mira Dontcheva, Wilmot Li, Michael S. Bernstein, and Daniela Steinsapir. 2015. Motif: Supporting Novice Creativity Through Expert Patterns. In Proceedings of the 33rd Annual ACM Conference on Human Factors in Computing Systems. ACM, New York, NY, USA, 1211-1220. https://doi.org/10.1145/2702123.2702507

[101] Joy Kim and Andres Monroy-Hernandez. 2016. Storia: Summarizing Social Media Content Based on Narrative Theory Using Crowdsourcing. In Proceedings of the 19th ACM Conference on Computer-Supported Cooperative Work \& Social Computing (CSCW' 16). ACM, New York, NY, USA, 1018-1027. https://doi.org/10.1145/2818048.2820072 
[102] Joy Kim, Sarah Sterman, Allegra Argent Beal Cohen, and Michael S. Bernstein. 2017. Mechanical Novel: Crowdsourcing Complex Work through Reflection and Revision. In Proceedings of the 2017 ACM Conference on Computer Supported Cooperative Work and Social Computing - CSCW '17. ACM Press, Portland, Oregon, USA, 233-245. https://doi.org/10.1145/2998181.2998196

[103] Annakaisa Kultima, Johannes Niemelä, Janne Paavilainen, and Hannamari Saarenpää. 2008. Designing Game Idea Generation Games. In Proceedings of the 2008 Conference on Future Play: Research, Play, Share. ACM, New York, NY, USA, 137-144. https://doi.org/10.1145/ 1496984.1497007

[104] David Ledo, Steven Houben, Jo Vermeulen, Nicolai Marquardt, Lora Oehlberg, and Saul Greenberg. 2018. Evaluation Strategies for HCI Toolkit Research. In Proceedings of the 2018 CHI Conference on Human Factors in Computing Systems (CHI '18). ACM, New York, NY, USA, 36:1-36:17. https://doi.org/10.1145/3173574.3173610

[105] Yong Liu, Jorge Goncalves, Denzil Ferreira, Bei Xiao, Simo Hosio, and Vassilis Kostakos. 2014. CHI 1994-2013: Mapping Two Decades of Intellectual Progress Through Co-word Analysis. In Proceedings of the 32Nd Annual ACM Conference on Human Factors in Computing Systems (CHI '14). ACM, New York, NY, USA, 3553-3562. https: //doi.org/10.1145/2556288.2556969

[106] Sara Ljungblad. 2009. Passive Photography from a Creative Perspective: "If I Would Just Shoot the Same Thing for Seven Days, It's Like... What's the Point?". In Proceedings of the SIGCHI Conference on Human Factors in Computing Systems. ACM, New York, NY, USA, 829-838. https://doi.org/10.1145/1518701.1518828

[107] Joanne Lo and Eric Paulos. 2014. ShrinkyCircuits: Sketching, Shrinking, and Formgiving for Electronic Circuits. In Proceedings of the 27th Annual ACM Symposium on User Interface Software and Technology. ACM, New York, NY, USA, 291-299. https://doi.org/10.1145/2642918. 2647421

[108] Fei Lu, Feng Tian, Yingying Jiang, Xiang Cao, Wencan Luo, Guang Li, Xiaolong Zhang, Guozhong Dai, and Hongan Wang. 2011. ShadowStory: Creative and Collaborative Digital Storytelling Inspired by Cultural Heritage. In Proceedings of the SIGCHI Conference on Human Factors in Computing Systems. ACM, New York, NY, USA, 1919-1928. https://doi.org/10.1145/1978942.1979221

[109] Andrés Lucero. 2012. Framing, Aligning, Paradoxing, Abstracting, and Directing: How Design Mood Boards Work. In Proceedings of the Designing Interactive Systems Conference. ACM, New York, NY, USA, 438-447. https://doi.org/10.1145/2317956.2318021

[110] Kurt Luther, Casey Fiesler, and Amy Bruckman. 2013. Redistributing Leadership in Online Creative Collaboration. In Proceedings of the 2013 Conference on Computer Supported Cooperative Work. ACM, New York, NY, USA, 1007-1022. https://doi.org/10.1145/2441776.2441891

[111] Neil Maiden, Konstantinos Zachos, Amanda Brown, George Brock, Lars Nyre, Aleksander Nygård Tonheim, Dimitris Apsotolou, and Jeremy Evans. 2018. Making the News: Digital Creativity Support for Journalists. In Proceedings of the 2018 CHI Conference on Human Factors in Computing Systems - CHI '18. ACM Press, Montreal QC, Canada, 1-11. https://doi.org/10.1145/3173574.3174049

[112] Nicolas Mangano, Alex Baker, Mitch Dempsey, Emily Navarro, and André van der Hoek. 2010. Software Design Sketching with Calico. In Proceedings of the IEEE/ACM International Conference on Automated Software Engineering. ACM, New York, NY, USA, 23-32. https://doi. org/10.1145/1858996.1859003

[113] Nicolas Mangano, Alex Baker, and André van der Hoek. 2008. Calico: A Prototype Sketching Tool for Modeling in Early Design. In Proceedings of the 2008 International Workshop on Models in Software Engineering. ACM, New York, NY, USA, 63-68. https://doi.org/10.

\section{$1145 / 1370731.1370747$}

[114] Charles Martin, Henry Gardner, Ben Swift, and Michael Martin. 2016. Intelligent Agents and Networked Buttons Improve Free-Improvised Ensemble Music-Making on Touch-Screens. In Proceedings of the 2016 CHI Conference on Human Factors in Computing Systems - CHI '16. ACM Press, Santa Clara, California, USA, 2295-2306. https: //doi.org/10.1145/2858036.2858269

[115] João Martinho and Teresa Chambel. 2009. ColorsInMotion: Interactive Visualization and Exploration of Video Spaces. In Proceedings of the 13th International MindTrek Conference: Everyday Life in the Ubiquitous Era. ACM, New York, NY, USA, 190-197. https: //doi.org/10.1145/1621841.1621876

[116] Dimitri Masson, Alexandre Demeure, and Gaelle Calvary. 2010. Magellan, an Evolutionary System to Foster User Interface Design Creativity. In Proceedings of the 2Nd ACM SIGCHI Symposium on Engineering Interactive Computing Systems. ACM, New York, NY, USA, 87-92. https://doi.org/10.1145/1822018.1822032

[117] J. Nathan Matias, Sayamindu Dasgupta, and Benjamin Mako Hill. 2016. Skill Progression in Scratch Revisited. In Proceedings of the 2016 CHI Conference on Human Factors in Computing Systems - CHI '16. ACM Press, Santa Clara, California, USA, 1486-1490. https: //doi.org/10.1145/2858036.2858349

[118] Nolwenn Maudet, Ghita Jalal, Philip Tchernavskij, Michel BeaudouinLafon, and Wendy E. Mackay. 2017. Beyond Grids: Interactive Graphical Substrates to Structure Digital Layout. In Proceedings of the 2017 CHI Conference on Human Factors in Computing Systems - CHI '17. ACM Press, Denver, Colorado, USA, 5053-5064. https://doi.org/10.1145/3025453.3025718

[119] Ali Mazalek, Sanjay Chandrasekharan, Michael Nitsche, Tim Welsh, Paul Clifton, Andrew Quitmeyer, Firaz Peer, Friedrich Kirschner, and Dilip Athreya. 2011. I'M in the Game: Embodied Puppet Interface Improves Avatar Control. In Proceedings of the Fifth International Conference on Tangible, Embedded, and Embodied Interaction. ACM, New York, NY, USA, 129-136. https://doi.org/10.1145/1935701.1935727

[120] Jon McCormack. 2007. Artificial Ecosystems for Creative Discovery. In Proceedings of the 9th Annual Conference on Genetic and Evolutionary Computation. ACM, New York, NY, USA, 301-307. https: //doi.org/10.1145/1276958.1277017

[121] Florian Mueller, Martin R. Gibbs, Frank Vetere, and Darren Edge. 2014. Supporting the Creative Game Design Process with Exertion Cards. In Proceedings of the SIGCHI Conference on Human Factors in Computing Systems. ACM, New York, NY, USA, 2211-2220. https: //doi.org/10.1145/2556288.2557272

[122] Michael D. Mumford, Robert Martin, Samantha Elliott, and Tristan McIntosh. 2018. Creative Failure: Why Can't People Solve Creative Problems. The fournal of Creative Behavior (Aug. 2018). https: //doi.org/10.1002/jocb.372

[123] Brad A. Myers, Ashley Lai, Tam Minh Le, YoungSeok Yoon, Andrew Faulring, and Joel Brandt. 2015. Selective Undo Support for Painting Applications. ACM Press, 4227-4236. https://doi.org/10.1145/ 2702123.2702543

[124] Naoto Nakazato, Shigeo Yoshida, Sho Sakurai, Takuji Narumi, Tomohiro Tanikawa, and Michitaka Hirose. 2014. Smart Face: Enhancing Creativity During Video Conferences Using Real-time Facial Deformation. In Proceedings of the 17th ACM Conference on Computer Supported Cooperative Work \& Social Computing. ACM, New York, NY, USA, 75-83. https://doi.org/10.1145/2531602.2531637

[125] Grace Ngai, Stephen C.F. Chan, Hong Va Leong, and Vincent T.Y. Ng. 2013. Designing I*CATch: A Multipurpose, Education-friendly Construction Kit for Physical and Wearable Computing. Trans. Comput. Educ. 13, 2 (July 2013), 7:1-7:30. https://doi.org/10.1145/2483710. 2483712 
[126] Tricia J. Ngoon, C. Ailie Fraser, Ariel S. Weingarten, Mira Dontcheva, and Scott Klemmer. 2018. Interactive Guidance Techniques for Improving Creative Feedback. In Proceedings of the 2018 CHI Conference on Human Factors in Computing Systems - CHI '18. ACM Press, Montreal QC, Canada, 1-11. https://doi.org/10.1145/3173574.3173629

[127] Nuno Jardim Nunes, Valentina Nisi, and Kara Rennert. 2016. beEco: Co-designing a Game with Children to Promote Environmental Awareness - A Case Study. In Proceedings of the 2016 CHI Conference Extended Abstracts on Human Factors in Computing Systems - CHI EA '16. ACM Press, Santa Clara, California, USA, 718-727. https://doi.org/10.1145/2851581.2851585

[128] Lora Oehlberg, Kyu Simm, Jasmine Jones, Alice Agogino, and Björn Hartmann. 2012. Showing is Sharing: Building Shared Understanding in Human-centered Design Teams with Dazzle. In Proceedings of the Designing Interactive Systems Conference. ACM, New York, NY, USA, 669-678. https://doi.org/10.1145/2317956.2318057

[129] Hyunjoo Oh, Jiffer Harriman, Abhishek Narula, Mark D. Gross, Michael Eisenberg, and Sherry Hsi. 2016. Crafting Mechatronic Percussion with Everyday Materials. In Proceedings of the TEI '16: Tenth International Conference on Tangible, Embedded, and Embodied Interaction - TEI '16. ACM Press, Eindhoven, Netherlands, 340-348. https://doi.org/10.1145/2839462.2839474

[130] Antti Oulasvirta, Anna Feit, Perttu Lähteenlahti, and Andreas Karrenbauer. 2017. Computational Support for Functionality Selection in Interaction Design. ACM Transactions on Computer-Human Interaction 24, 5 (Oct. 2017), 1-30. https://doi.org/10.1145/3131608

[131] Ozgu Ozkan and Fehmi Dogan. 2013. Cognitive strategies of analogical reasoning in design: Differences between expert and novice designers. Design Studies 34, 2 (March 2013), 161-192. https: //doi.org/10.1016/j.destud.2012.11.006

[132] Ingrid Pettersson, Florian Lachner, Anna-Katharina Frison, Andreas Riener, and Andreas Butz. 2018. A Bermuda Triangle?: A Review of Method Application and Triangulation in User Experience Evaluation. In Proceedings of the 2018 CHI Conference on Human Factors in Computing Systems (CHI '18). ACM, New York, NY, USA, 461:1-461:16. https://doi.org/10.1145/3173574.3174035

[133] Florian Pinel and Lav R. Varshney. 2014. Computational Creativity for Culinary Recipes. In CHI '14 Extended Abstracts on Human Factors in Computing Systems. ACM, New York, NY, USA, 439-442. https: //doi.org/10.1145/2559206.2574794

[134] Cecil Piya, Vinayak, Senthil Chandrasegaran, Niklas Elmqvist, and Karthik Ramani. 2017. Co-3Deator: A Team-First Collaborative 3D Design Ideation Tool. In Proceedings of the 2017 CHI Conference on Human Factors in Computing Systems - CHI '17. ACM Press, Denver, Colorado, USA, 6581-6592. https://doi.org/10.1145/3025453.3025825

[135] Jonathan A. Plucker, Ronald A. Beghetto, and Gayle T. Dow. 2004 Why Isn't Creativity More Important to Educational Psychologists? Potentials, Pitfalls, and Future Directions in Creativity Research. Educational Psychologist 39, 2 (June 2004), 83-96. https://doi.org/10 1207/s15326985ep3902_1

[136] Thorsten Prante, Carsten Magerkurth, and Norbert Streitz. 2002. Developing CSCW Tools for Idea Finding -: Empirical Results and Implications for Design. In Proceedings of the 2002 ACM Conference on Computer Supported Cooperative Work. ACM, New York, NY, USA, 106-115. https://doi.org/10.1145/587078.587094

[137] Daniel Rees Lewis, Emily Harburg, Elizabeth Gerber, and Matthew Easterday. 2015. Building Support Tools to Connect Novice Designers with Professional Coaches. In Proceedings of the 2015 ACM SIGCHI Conference on Creativity and Cognition. ACM, New York, NY, USA, 43-52. https://doi.org/10.1145/2757226.2757248

[138] Christian Remy, Oliver Bates, Alan Dix, Vanessa Thomas, Mike Hazas, Adrian Friday, and Elaine M. Huang. 2018. Evaluation beyond Usability: Validating Sustainable HCI Research. In Proceedings of the 2018
CHI Conference on Human Factors in Computing Systems (CHI '18).

[139] Christian Remy, Oliver Bates, Jennifer Mankoff, and Adrian Friday. 2018. Evaluating HCI Research beyond Usability. In Extended Abstracts of the 2018 CHI Conference on Human Factors in Computing Systems. Montreal, Canada.

[140] Mel Rhodes. 1961. An analysis of creativity. The Phi Delta Kappan 42, 7 (1961), 305-310.

[141] Daniela K. Rosner. 2010. Mediated Crafts: Digital Practices Around Creative Handwork. In CHI '10 Extended Abstracts on Human Factors in Computing Systems (CHI EA '10). ACM, New York, NY, USA, 29552958. https://doi.org/10.1145/1753846.1753894

[142] Daniela K. Rosner and Kimiko Ryokai. 2009. Reflections on Craft: Probing the Creative Process of Everyday Knitters. In Proceedings of the Seventh ACM Conference on Creativity and Cognition. ACM, New York, NY, USA, 195-204. https://doi.org/10.1145/1640233.1640264

[143] Daniela K. Rosner and Kimiko Ryokai. 2010. Spyn: Augmenting the Creative and Communicative Potential of Craft. In Proceedings of the SIGCHI Conference on Human Factors in Computing Systems. ACM, New York, NY, USA, 2407-2416. https://doi.org/10.1145/1753326. 1753691

[144] Mark A Runco. 2014. Creativity: Theories and themes: Research, development, and practice (2 ed.). Elsevier Science/Academic Press, London.

[145] Mark A Runco and Ivonne Chand. 1995. Cognition and creativity. Educational psychology review 7, 3 (1995), 243-267.

[146] Mark A. Runco and Garrett J. Jaeger. 2012. The Standard Definition of Creativity. Creativity Research fournal 24, 1 (Jan. 2012), 92-96. https://doi.org/10.1080/10400419.2012.650092

[147] R Keith Sawyer. 2006. Explaining creativity: The science of human innovation (2 ed.). Oxford University Press, Oxford, UK.

[148] R. Keith Sawyer. 2012. Explaining Creativity: The Science of Human Innovation. Oxford University Press, USA. Google-Books-ID: auAXfVwNAJoC.

[149] Jana Schumann, Patrick C. Shih, David F. Redmiles, and Graham Horton. 2012. Supporting Initial Trust in Distributed Idea Generation and Idea Evaluation. In Proceedings of the 17th ACM International Conference on Supporting Group Work. ACM, New York, NY, USA, 199-208. https://doi.org/10.1145/2389176.2389207

[150] Duane F. Shell, Leen-Kiat Soh, Abraham E. Flanigan, Markeya S. Peteranetz, and Elizabeth Ingraham. 2017. Improving Students' Learning and Achievement in CS Classrooms through Computational Creativity Exercises that Integrate Computational and Creative Thinking. In Proceedings of the 2017 ACM SIGCSE Technical Symposium on Computer Science Education - SIGCSE '17. ACM Press, Seattle, Washington, USA, 543-548. https://doi.org/10.1145/3017680.3017718

[151] Renata M. Sheppard, Mahsa Kamali, Raoul Rivas, Morihiko Tamai, Zhenyu Yang, Wanmin Wu, and Klara Nahrstedt. 2008. Advancing Interactive Collaborative Mediums Through Tele-immersive Dance (TED): A Symbiotic Creativity and Design Environment for Art and Computer Science. In Proceedings of the 16th ACM International Conference on Multimedia. ACM, New York, NY, USA, 579-588. https://doi.org/10.1145/1459359.1459437

[152] Ben Shneiderman. 2000. Creating Creativity: User Interfaces for Supporting Innovation. ACM Trans. Comput.-Hum. Interact. 7, 1 (March 2000), 114-138. https://doi.org/10.1145/344949.345077

[153] Ben Shneiderman. 2001. Supporting creativity with advanced information-abundant user interfaces. In Frontiers of human-centered computing, online communities and virtual environments. Springer, 469-480.

[154] Ben Shneiderman. 2002. Creativity Support Tools. Commun. ACM 45, 10 (Oct. 2002), 116-120. https://doi.org/10.1145/570907.570945 
[155] Ben Shneiderman. 2007. Creativity Support Tools: Accelerating Discovery and Innovation. Commun. ACM 50, 12 (Dec. 2007), 20-32. https://doi.org/10.1145/1323688.1323689

[156] Ben Shneiderman. 2009. Creativity Support Tools: A Grand Challenge for HCI Researchers. In Engineering the User Interface, Miguel Redondo, Crescencio Bravo, and Manuel Ortega (Eds.). Springer London, London, 1-9. https://doi.org/10.1007/978-1-84800-136-7_1

[157] Ben Shneiderman, Tom Hewett, Gerhard Fischer, Pamela Jennings, Mary Czerwinski, Kumiyo Nakakoji, Mitch Resnick, Brad Myers, Jay Nunamaker, Linda Candy, Ernest Edmonds, Randy Pausch, Mike Eisenberg, Elisa Giaccardi, Ted Selker, Elisabeth Sylvan, and Michael Terry. 2006. Creativity Support Tools: Report From a U.S. National Science Foundation Sponsored Workshop. Microsoft Research 20 (May 2006).

[158] Maria Shugrina, Jingwan Lu, and Stephen Diverdi. 2017. Playful palette: an interactive parametric color mixer for artists. ACM Transactions on Graphics 36, 4 (July 2017), 1-10. https://doi.org/10.1145/ 3072959.3073690

[159] Pao Siangliulue, Joel Chan, Steven P. Dow, and Krzysztof Z. Gajos. 2016. IdeaHound: Improving Large-scale Collaborative Ideation with Crowd-Powered Real-time Semantic Modeling. In Proceedings of the 29th Annual Symposium on User Interface Software and Technology UIST '16. ACM Press, Tokyo, Japan, 609-624. https://doi.org/10.1145/ 2984511.2984578

[160] Pao Siangliulue, Joel Chan, Krzysztof Z. Gajos, and Steven P. Dow. 2015. Providing Timely Examples Improves the Quantity and Quality of Generated Ideas. In Proceedings of the 2015 ACM SIGCHI Conference on Creativity and Cognition. ACM, New York, NY, USA, 83-92. https: //doi.org/10.1145/2757226.2757230

[161] Vikash Singh, Celine Latulipe, Erin Carroll, and Danielle Lottridge. 2011. The Choreographer's Notebook: A Video Annotation System for Dancers and Choreographers. In Proceedings of the 8th ACM Conference on Creativity and Cognition. ACM, New York, NY, USA, 197-206. https://doi.org/10.1145/2069618.2069653

[162] Dorothé Smit, Thomas Grah, Martin Murer, Vincent van Rheden, and Manfred Tscheligi. 2018. MacroScope: First-Person Perspective in Physical Scale Models. In Proceedings of the Twelfth International Conference on Tangible, Embedded, and Embodied Interaction - TEI '18. ACM Press, Stockholm, Sweden, 253-259. https://doi.org/10.1145/ 3173225.3173276

[163] Norbert A. Streitz, Jörg Geißler, Torsten Holmer, Shin'ichi Konomi, Christian Müller-Tomfelde, Wolfgang Reischl, Petra Rexroth, Peter Seitz, and Ralf Steinmetz. 1999. i-LAND: An Interactive Landscape for Creativity and Innovation. In Proceedings of the SIGCHI Conference on Human Factors in Computing Systems. ACM, New York, NY, USA, 120-127. https://doi.org/10.1145/302979.303010

[164] Anne Sullivan, Mirjam Palosaari Eladhari, and Michael Cook. 2018. Tarot-based narrative generation. In Proceedings of the 13th International Conference on the Foundations of Digital Games - FDG '18. ACM Press, Malm\&\#246; Sweden, 1-7. https://doi.org/10.1145/3235765. 3235819

[165] Wei Sun, Ying Li, Anshul Sheopuri, and Thales Teixeira. 2018. Computational Creative Advertisements. In Companion of the The Web Conference 2018 on The Web Conference 2018 - WWW'18. ACM Press, Lyon, France, 1155-1162. https://doi.org/10.1145/3184558.3191549

[166] Robyn Taylor, John Bowers, Bettina Nissen, Gavin Wood, Qasim Chaudhry, Peter Wright, Lindsey Bruce, Sarah Glynn, Helen Mallinson, and Roy Bearpark. 2015. Making Magic: Designing for Open Interactions in Museum Settings. In Proceedings of the 2015 ACM SIGCHI Conference on Creativity and Cognition. ACM, New York, NY, USA, 313-322. https://doi.org/10.1145/2757226.2757241

[167] Cesar Torres, Wilmot Li, and Eric Paulos. 2016. ProxyPrint: Supporting Crafting Practice through Physical Computational Proxies.
In Proceedings of the 2016 ACM Conference on Designing Interactive Systems - DIS '16. ACM Press, Brisbane, QLD, Australia, 158-169. https://doi.org/10.1145/2901790.2901828

[168] Cesar Torres and Eric Paulos. 2015. MetaMorphe: Designing Expressive 3D Models for Digital Fabrication. In Proceedings of the 2015 ACM SIGCHI Conference on Creativity and Cognition. ACM, New York, NY, USA, 73-82. https://doi.org/10.1145/2757226.2757235

[169] Ambra Trotto and Caroline Hummels. 2013. Engage Me, Do!: Engagement Catalysers to Ignite a (Design) Conversation. In Proceedings of the 6th International Conference on Designing Pleasurable Products and Interfaces. ACM, New York, NY, USA, 136-145. https://doi.org/10.1145/2513506.2513521

[170] Theophanis Tsandilas, Catherine Letondal, and Wendy E. Mackay. 2009. Musink: Composing Music Through Augmented Drawing. In Proceedings of the SIGCHI Conference on Human Factors in Computing Systems. ACM, New York, NY, USA, 819-828. https://doi.org/10.1145/ 1518701.1518827

[171] Rajan Vaish, Shirish Goyal, Amin Saberi, and Sharad Goel. 2018. Creating Crowdsourced Research Talks at Scale. In Proceedings of the 2018 World Wide Web Conference on World Wide Web - WWW '18. ACM Press, Lyon, France, 1-11. https://doi.org/10.1145/3178876. 3186031

[172] Graham Wallas. 1926. The art of thought. Harcourt, Brace and Company, New York.

[173] Hao-Chuan Wang, Dan Cosley, and Susan R. Fussell. 2010. Idea Expander: Supporting Group Brainstorming with Conversationally Triggered Visual Thinking Stimuli. In Proceedings of the 2010 ACM Conference on Computer Supported Cooperative Work. ACM, New York, NY, USA, 103-106. https://doi.org/10.1145/1718918.1718938

[174] Hao-Chuan Wang, Susan R. Fussell, and Dan Cosley. 2011. From Diversity to Creativity: Stimulating Group Brainstorming with Cultural Differences and Conversationally-retrieved Pictures. In Proceedings of the ACM 2011 Conference on Computer Supported Cooperative Work. ACM, New York, NY, USA, 265-274. https://doi.org/10.1145/1958824. 1958864

[175] Tianyi Wang, Ke Huo, Pratik Chawla, Guiming Chen, Siddharth Banerjee, and Karthik Ramani. 2018. Plain2Fun: Augmenting Ordinary Objects with Interactive Functions by Auto-Fabricating Surface Painted Circuits. In Proceedings of the 2018 on Designing Interactive Systems Conference 2018 - DIS '18. ACM Press, Hong Kong, China, 1095-1106. https://doi.org/10.1145/3196709.3196791

[176] Kento Watanabe, Yuichiroh Matsubayashi, Kentaro Inui, Tomoyasu Nakano, Satoru Fukayama, and Masataka Goto. 2017. LyriSys: An Interactive Support System for Writing Lyrics Based on Topic Transition. In Proceedings of the 22nd International Conference on Intelligent User Interfaces - IUI '17. ACM Press, Limassol, Cyprus, 559-563. https://doi.org/10.1145/3025171.3025194

[177] Robert W. Weisberg. 2006. Expertise and Reason in Creative Thinking: Evidence from Case Studies and the Laboratory. In Creativity and reason in cognitive development. Cambridge University Press, New York, NY, US, 7-42. https://doi.org/10.1017/CBO9780511606915.003

[178] Karl D.D. Willis, Juncong Lin, Jun Mitani, and Takeo Igarashi. 2010. Spatial Sketch: Bridging Between Movement \& Fabrication. In Proceedings of the Fourth International Conference on Tangible, Embedded, and Embodied Interaction. ACM, New York, NY, USA, 5-12. https://doi.org/10.1145/1709886.1709890

[179] Karl D.D. Willis, Cheng Xu, Kuan-Ju Wu, Golan Levin, and Mark D. Gross. 2010. Interactive Fabrication: New Interfaces for Digital Fabrication. In Proceedings of the Fifth International Conference on Tangible, Embedded, and Embodied Interaction. ACM, New York, NY, USA, 6972. https://doi.org/10.1145/1935701.1935716 
[180] Jun Xie, Aaron Hertzmann, Wilmot Li, and Holger Winnemöller. 2014 PortraitSketch: Face Sketching Assistance for Novices. In Proceedings of the 27th Annual ACM Symposium on User Interface Software and Technology. ACM, New York, NY, USA, 407-417. https://doi.org/10. $1145 / 2642918.2647399$

[181] Anbang Xu, Shih-Wen Huang, and Brian Bailey. 2014. Voyant: Generating Structured Feedback on Visual Designs Using a Crowd of Non-experts. In Proceedings of the 17th ACM Conference on Computer Supported Cooperative Work \& Social Computing. ACM, New York, NY, USA, 1433-1444. https://doi.org/10.1145/2531602.2531604

[182] Junichi Yamaoka and Yasuaki Kakehi. 2013. dePENd: Augmented Handwriting System Using Ferromagnetism of a Ballpoint Pen. In Proceedings of the 26th Annual ACM Symposium on User Interface Software and Technology. ACM, New York, NY, USA, 203-210. https: //doi.org/10.1145/2501988.2502017

[183] Junichi Yamaoka, Ryuma Niiyama, and Yasuaki Kakehi. 2017. BlowFab: Rapid Prototyping for Rigid and Reusable Objects using Inflation of Laser-cut Surfaces. In Proceedings of the 30th Annual ACM Symposium on User Interface Software and Technology - UIST '17. ACM Press, Qu\&\#233;bec City, QC, Canada, 461-469. https://doi.org/10.1145/ 3126594.3126624

[184] Tom Yeh and Jeeeun Kim. 2018. CraftML: 3D Modeling is Web Programming. In Proceedings of the 2018 CHI Conference on Human Factors in Computing Systems - CHI '18. ACM Press, Montreal QC, Canada, 1-12. https://doi.org/10.1145/3173574.3174101

[185] Daisy Yoo, Alina Huldtgren, Jill Palzkill Woelfer, David G. Hendry, and Batya Friedman. 2013. A Value Sensitive Action-reflection Model: Evolving a Co-design Space with Stakeholder and Designer Prompts. In Proceedings of the SIGCHI Conference on Human Factors in Computing Systems. ACM, New York, NY, USA, 419-428. https://doi.org/10.1145/2470654.2470715

[186] Sang Ho Yoon, Ansh Verma, Kylie Peppler, and Karthik Ramani. 2015. HandiMate: Exploring a Modular Robotics Kit for Animating Crafted Toys. In Proceedings of the 14th International Conference on Interaction Design and Children. ACM, New York, NY, USA, 11-20. https://doi. org/10.1145/2771839.2771841
[187] Natsuko Yoshida, Shogo Fukushima, Daiya Aida, and Takeshi Naemura. 2016. Practical Study of Positive-feedback Button for Brainstorming with Interjection Sound Effects. In Proceedings of the 2016 CHI Conference Extended Abstracts on Human Factors in Computing Systems - CHI EA '16. ACM Press, Santa Clara, California, USA, 13221328. https://doi.org/10.1145/2851581.2892418

[188] Lixiu Yu, Aniket Kittur, and Robert E. Kraut. 2014. Distributed Analogical Idea Generation: Inventing with Crowds. In Proceedings of the 32Nd Annual ACM Conference on Human Factors in Computing Systems. ACM, New York, NY, USA, 1245-1254. https://doi.org/10. 1145/2556288.2557371

[189] Lixiu Yu and Jeffrey V. Nickerson. 2011. Cooks or Cobblers?: Crowd Creativity Through Combination. In Proceedings of the SIGCHI Conference on Human Factors in Computing Systems. ACM, New York, NY, USA, 1393-1402. https://doi.org/10.1145/1978942.1979147

[190] Yupeng Zhang, Teng Han, Zhimin Ren, Nobuyuki Umetani, Xin Tong, Yang Liu, Takaaki Shiratori, and Xiang Cao. 2013. BodyAvatar: Creating Freeform 3D Avatars Using First-person Body Gestures. In Proceedings of the 26th Annual ACM Symposium on User Interface Software and Technology. ACM, New York, NY, USA, 387-396. https://doi.org/10.1145/2501988.2502015

[191] Zhenpeng Zhao, Sriram Karthik Badam, Senthil Chandrasegaran, Deok Gun Park, Niklas L.E. Elmqvist, Lorraine Kisselburgh, and Karthik Ramani. 2014. skWiki: A Multimedia Sketching System for Collaborative Creativity. In Proceedings of the 32Nd Annual ACM Conference on Human Factors in Computing Systems. ACM, New York, NY, USA, 1235-1244. https://doi.org/10.1145/2556288.2557394

[192] Clement Zheng, Ellen Yi-Luen Do, and Jim Budd. 2017. Joinery: Parametric Joint Generation for Laser Cut Assemblies. In Proceedings of the 2017 ACM SIGCHI Conference on Creativity and Cognition - C\&C '17. ACM Press, Singapore, Singapore, 63-74. https://doi.org/10.1145/ 3059454.3059459

[193] Li Zhu, Piero Mussio, and Barbara Rita Barricelli. 2010. Hive-mind Space Model for Creative, Collaborative Design. In Proceedings of the 1st DESIRE Network Conference on Creativity and Innovation in Design. Desire Network, Lancaster, UK, UK, 121-130. http://dl.acm. org/citation.cfm?id=1854969.1854988 